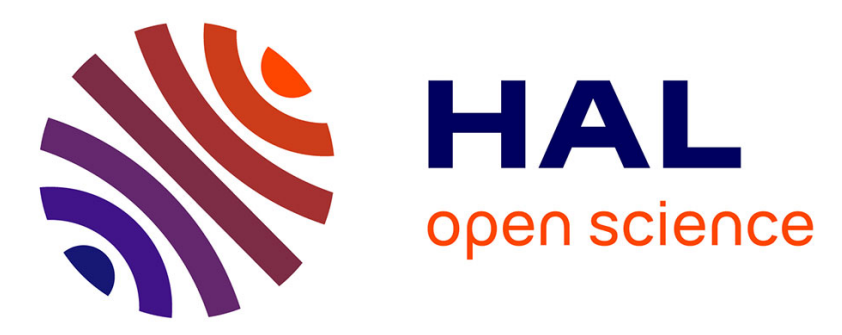

\title{
Functional Analysis of the Sensory Motor Pathway of Resistance Reflex in Crayfish. I. Multisensory Coding and Motor Neuron Monosynaptic Responses
}

François Clarac, Daniel Cattaert, Didier Le Ray

\section{- To cite this version:}

François Clarac, Daniel Cattaert, Didier Le Ray. Functional Analysis of the Sensory Motor Pathway of Resistance Reflex in Crayfish. I. Multisensory Coding and Motor Neuron Monosynaptic Responses. Journal of Neurophysiology, 1997, 10.1152/jn.1997.78.6.3133 . hal-02346666

\section{HAL Id: hal-02346666 https://hal.science/hal-02346666}

Submitted on 7 Nov 2019

HAL is a multi-disciplinary open access archive for the deposit and dissemination of scientific research documents, whether they are published or not. The documents may come from teaching and research institutions in France or abroad, or from public or private research centers.
L'archive ouverte pluridisciplinaire HAL, est destinée au dépôt et à la diffusion de documents scientifiques de niveau recherche, publiés ou non, émanant des établissements d'enseignement et de recherche français ou étrangers, des laboratoires publics ou privés. 
FUNCTIONAL ANALYSIS OF THE SENSORY MOTOR PATHWAY OF RESISTANCE REFLEX IN CRAYFISH. I- MULTI-SENSORY CODING AND MOTOR NEURON MONOSYNAPTIC RESPONSES.

Didier LE RAY, François CLARAC, and Daniel CATTAERT

Laboratoire de Neurobiologie et Mouvements, CNRS, 31 chemin Joseph Aiguier, Marseille, France.

Running title: Sensory coding and motor neurons

Correspondence: D. LE RAY, Laboratoire Neurobiologie et Mouvements, CNRS, 31 chemin Joseph Aiguier, 13402 Marseille cedex 20, FRANCE.

Tel: (33) 4. 91.16.43.45

Fax: (33) 4. 91.77.50.84

E-mail: leray@1nf.cnrs-mrs.fr 


\section{ABSTRACT}

The in vitro preparation of the fifth thoracic ganglion of the crayfish was used to detail the negative feedback loop involved in the control of passive movements of the leg. Releasesensitive primary afferents issued from the coxo-basipodite chordotonal organ (CBCO), a proprioceptor which strand is released by upward movement of the leg, monosynaptically connect the depressor motor neurons (Dep MNs). Extracellular identification of sensory units from the $\mathrm{CBCO}$ neurogram allowed us to determine the global coding of a sine wave movement, imposed from the most released position of the CBCO strand. Intracellular recordings from sensory terminals (CBTs) and ramp movement stimulations applied to the $\mathrm{CBCO}$ strand allowed us to characterize two groups of release-sensitive $\mathrm{CBCO}$ fibers. The first group, divided into two subgroups (phasic and phasico-tonic), is characterized by discontinuous firing patterns: phasic CBTs fired exclusively during release movements; phasico-tonic CBTs displayed both a phasic firing and a tonic discharge during the more released plateaus. The second group was continuously firing whatever the movement, with higher frequencies during the release phase of the movement stimulation. All CBTs displayed a marked sensitivity for release movements while only the phasico-tonic ones showed a clear sensitivity to maintained positions. A previous study described different subtypes among the 12 Dep MNs of the hemi-ganglion: only nine Dep MNs (one assistant and eight resistant) are monosynaptically connected by $\mathrm{CBCO}$ afferents. Systematic intracellular recordings from all resistant Dep MNs, performed in high divalent cation saline, allowed us to describe two shapes of monosynaptic resistance reflex responses. A phasic response was characterized by bursts of EPSPs occurring exclusively during CBCO strand release movements. A phasicotonic response was characterized by a progressive depolarization occurring all along the release phase of the stimulation: during maintained released positions, the amplitude of the 
sustained depolarization was position-dependent; in addition, each release movement produced a phasic burst of EPSPs in the MN. The parallel study of the Dep MN properties failed to point out any correlation between the type of reflex response recorded from the MN and the MN intrinsic properties, which would indicate that the type of MN response is entirely determined by the afferent messages it receives. This question is addressed in a companion paper. 


\section{INTRODUCTION}

In our knowledge on motor control regulation, the stretch reflex is a very widespread phenomenon described in all groups of vertebrates and invertebrates (Granit 1955; Pringle 1961). Studied in details in the past, this reflex was first considered as rigid and stereotyped, but the concept of reflex has evolved recently in parallel with the data accumulated on the central pattern generator (Barnes and Gladden 1985; Clarac 1991; Pearson 1993).

In the crustacean walking legs, each joint possesses one or two mechano-receptors, the chordotonal organs, able to record the different parameters of position and movements (Bush and Laverack 1982; Whitear 1962; Wiersma 1959). They are composed of an elastic strand in which ten to hundred bipolar cells are inserted. Mill (1976) defined four different classes of sensory afferents in the dactyl chordotonal organ. Two are sensitive to changes of the chordotonal organ strand length; they operate in opposite direction, one being stretchsensitive, the other release-sensitive. The two others code the strand length (stretched or released states of the strand). Considering the overall chordotonal discharge, these receptors are mainly activated during extreme angular movements and positions, and minimally activated for mid-ramp movements and positions. Bush (1962) demonstrated that chordotonal organs are able to induce a stretch reflex, called a resistance reflex, which consists in the activation of the passively stretched muscle. The stretch reflex is not limited to its proper joint but can spread out on other joints or even on other legs (Clarac 1977; Vedel \& Clarac 1979). Intensity and gain of this reflex appear to be very variable and may lead to complete reversal. In the stick insect, Bässler (1976), in the crab, Di Caprio and Clarac (1981), and in the crayfish, Skorupski and Sillar (1986) demonstrated that the same mechano-receptor is able depending upon "the central state" of the CNS to change a resistance reflex into an assistance 
reflex. Such variability has been similarly found in mammals (Pearson 1993) and in human (Duysens and Tax 1994).

In the arthropods, intracellular studies have demonstrated that resistance reflex involves monosynaptic and polysynaptic connections (Bässler 1993; Burrows 1975). The variability of the reflex has often been associated with interneurons which are inserted within the reflex pathway, between sensory terminals and MNs (Burrows 1992; Büschges and Schmitz 1991; Büschges and Wolf 1995; Le Ray and Cattaert 1997). However in the crayfish, monosynaptic connections between the coxo-basal chordotonal organ $(\mathrm{CBCO})$ and the levator (Lev) and depressor (Dep) MNs that command the coxo-basal joint, have been demonstrated to be responsible for efficient resistance reflexes (El Manira et al. 1991).

The $\mathrm{CBCO}$ contains 40 afferents, half are sensitive to $\mathrm{CBCO}$ stretch (corresponding to downward movement of the leg in intact animal) and half to $\mathrm{CBCO}$ release (corresponding to upward movement of the leg in intact animal); the levator pool contains $19 \mathrm{MNs}$ and the depressor pool 12 MNs. To study the determinants of the monosynaptic sensory-motor relationship, we have used a saline enriched in calcium and magnesium (x 2.5) in order to suppress the majority of the polysynaptic connections (Berry and Pentreath 1976) and keep intact the direct $\mathrm{CBCO}$ afferent-motoneuronal pathways.

Up to now, sensory afferents have been considered depending upon the temporal parameters of their firing as phasic and tonic units, corresponding roughly to movement and position coding fibers. In the past, the classification of MNs was mainly established upon the types of muscle fiber they innervate: a $\mathrm{MN}$ is considered as phasic when its electrical stimulation elicits a twitch contraction, and as tonic when it induces a slow postural response. In this paper we analyze in detail the coding of movement parameters by sensory afferents and the output response of the motor neurons (MNs). Using new computer data processing, it is possible to identify individually each sensory afferent in a sensory nerve discharge, based 
upon the shape of each extracellular action potential. To simplify this study we focused on the release-sensitive $\mathrm{CBCO}$ afferent fibers and the 9 Dep MNs that received monosynaptic inputs from the CBCO fibers (three of the 12 Dep MNs do not receive any direct CBCO inputs; Le Ray and Cattaert 1997). Therefore, we restrained mechanical movements imposed to the CBCO strand to its most released range, where this reflex is the most efficient. In this paper, we classified the different release-sensitive sensory afferents, and the different postsynaptic Dep MNs according to a qualitative and quantitative analysis of their responses and properties. In the following paper, using paired intracellular recordings, the wiring of the sensory-motor connections will be established and the role of specific synaptic parameters controlling MN response will be presented.

\section{METHODS}

\section{Preparation.}

Results are based on more than 130 intracellular recordings from CBTs and Dep MNs performed on adult male and female crayfish, Pacifastacus leniusculus and Procambarus clarkii. Animals were maintained in aquarium at $18^{\circ} \mathrm{C}$ and fed once a week.

The in vitro preparation (Fig. 1A) consisted of the last three thoracic ganglia along with the two couples of antagonistic motor nerves innervating the two proximal joints of the $5^{\text {th }}$ leg (Promotor/Remotor and Depressor/Levators). The CBCO, which encodes the vertical movements of the leg, was dissected out together with its sensory nerve (CB nerve). The preparation was pinned down dorsal side up in a Sylgard-lined Petri dish and superfused with oxygenated crayfish saline.

Stimulations / Recordings. 
Extracellular recordings and nerve stimulations were performed using platinum electrodes contacting the nerves, isolated from bath with Vaseline, and directed to a 4-channel differential AC amplifier (A-M Systems). Single and paired intracellular recordings from CBTs and MNs (Fig. 1B) were realized with thin-walled glass micro-electrodes filled with a potassium chloride solution $(3 \mathrm{M})$ and having a 25-30 $\mathrm{M} \Omega$ resistance. The signals were amplified by an Axoclamp 2B (Axon Instruments). Intracellular current pulses and nerve stimulations were controlled by an 8-channel digital stimulator (A.M.P.I.). All signals were monitored on a eight channel oscilloscope, a four channel digital oscilloscope (Yokogawa DL 1200) and stored on D.A.T. tapes (BioLogics digital tape recorder) and digitized on a PCbased computer through an $\mathrm{A} / \mathrm{D}$ interface (from Cambridge Electronic Device, CED 1401PLUS). Intracellular and extracellular recordings were digitized at 5-10 kHz and written to disk.

An electromechanical puller (Ling Dynamic systems Ltd.) commanded by a homemade controller was used to stretch and release of the $\mathrm{CBCO}$ strand, according to sinusoïdal (Fig. 1, A, C and D) or ramp (Fig. 4) protocols. Ramp stimulations are very suitable for separating position from movement sensitivities in intracellular recordings from one CBT. However, this procedure tends to synchronize the firing at the onset of each ramp movement which makes it very difficult to separate the different units within the neurogram. Therefore sine wave movements were used during experiments in which $\mathrm{CBCO}$ neurograms were analyzed. Stretching stimulations were performed from the most released position of the $\mathrm{CBCO}$ strand and total movement amplitude was one third of the released $\mathrm{CBCO}$ strand length $(1 \mathrm{~mm}-1.8 \mathrm{~mm})$. It almost corresponds to the angular range in which the leg moves during locomotion. Imposed movements elicit stretch and release of the CBCO strand, as real leg movements do. The movement control voltage traces were visualized on the oscilloscopes and stored on both tape and computer. 
Salines.

A normal saline ( $\mathrm{NaCl}: 195 \mathrm{mM}, \mathrm{KCl}: 5 \mathrm{mM}, \mathrm{CaCl}_{2}: 13 \mathrm{mM}, \mathrm{MgCl}_{2}: 2 \mathrm{mM}$ ), was used to perform the sensory coding analysis. Because strong central synaptic inputs masked the monosynaptic sensory inputs from the CBCO, the Dep MN responses were analyzed with saline in which divalent cation concentrations were increased $\left(\mathrm{CaCl}_{2}: 34 \mathrm{mM}, \mathrm{MgCl}_{2}: 6.4\right.$ $\mathrm{mM}$, with the sodium concentration reduced accordingly); it was perfused exclusively on thoracic ganglia, in order to raise the activation threshold of all central neurons without affecting the CBCO sensory inputs (Fig. 8). Saline solutions were buffered with $3 \mathrm{mM} \mathrm{N}-[2-$ Hydroxyethyl] piperazine-N'-[2-ethanesulfonic acid] (Hepes) and $\mathrm{pH}$ adjusted at 7.7 at $15^{\circ} \mathrm{C}$.

Analysis.

Signals were analyzed using the CED programs SPIKE2 and SIGAVG. The "Wave Marker" SPIKE2 program was used to classify the different profiles of extracellular spikes recorded from the $\mathrm{CBCO}$ nerve. Circular statistics were used to study the sensory coding of the cyclic imposed movement. Each sensory unit was identified over several movement cycles. Each cycle is defined from the starting of the release phase (chosen as zero) to the next release phase (chosen as 360 degrees). Each unit is figured by a unit vector $\vec{v}_{i}$, with a phase angle according to its occurrence in the stimulus cycle. The resulting vector $\vec{R}$ is the sum of all unit vectors, divided by the number (n) of spikes (Fig. 2A):

$$
\begin{gathered}
\vec{R}=\frac{\sum_{n} \vec{v}_{i}}{n}, \\
\|\vec{R}\|=\sqrt{R_{x}{ }^{2}+R_{y}{ }^{2}}, \\
\alpha=\operatorname{ArcTan}\left(\frac{R_{y}}{R_{x}}\right),
\end{gathered}
$$

with $\mathrm{R}_{\mathrm{x}}$ and $\mathrm{R}_{\mathrm{y}}$ representing the $\mathrm{x}$ and y coordinates of the resulting vector $\vec{R}$. 
The resulting vector length $(\|\vec{R}\|)$ has a value between 0 and 1 , and is a measure for the dispersion of the spikes within a stimulus cycle. A value of zero means that the spikes are evenly distributed; a value of one would indicate that all spikes occurred at the same phase. The frequency distribution of $\|\vec{R}\|$ over all experiments (Fig. 2B) is bimodal, the separation between the two peaks being 0.3 . Therefore, units with $\|\vec{R}\|$ value below 0.3 were considered as non-specific units (Fig. 2C), whereas the others were classified as release or stretchsensitive units.

SPIKE2 scripts were used to analyze, for each part of the mechanical stimulation, the instantaneous and mean firing frequencies from CBTs, and the Dep MN responses. SIGAVG program was used to record $\mathrm{MN}$ response to various intracellular current pulses, in order to realize the V/I curves from Dep MNs. Statistical analysis and regressions were performed with the GraphPad Prism statistic programs.

\section{RESULTS}

As shown in figure 1, C and D, the mechanical stimulation of the CBCO strand is able to produce a reflex activity in the in vitro preparation. This is characterized by the discharge of the sensory units that can be recorded extracellularly in the CBCO neurogram and intracellularly in the CBTs (Fig. 1C). This sensory firing induces, in the postsynaptic Dep MN, a depolarization of its membrane potential (Fig. 1D) because of the summation of each compound EPSP.

I - Analysis of the CBCO sensory coding of the leg movements. 
Two complementary studies have been performed to describe the coding of the CBCO sensory informations. First, from the neurogram, an extracellular approach allowed to characterize in a general manner the different CBCO units. Because of the limitations of this method we realized a second analysis, the intracellular characterization of the CBCO fibers. To facilitate our work, we focused the intracellular study on the release-sensitive afferents, impaled in their terminals.

I A - Extracellular study from the CBCO neurogram.

The extracellular study has been performed from a sinusoidal movement stimulation of the $\mathrm{CBCO}$ strand. In the angular range of the imposed sinusoidal movement, and depending on the preparation, about the half of the $\mathrm{CBCO}$ units were activated as shown on figure $2 \mathrm{C}$ and figure 3. In our conditions, release-sensitive afferents were predominantly recruited $(11 / 20 \pm 2$ release-sensitive and 7/20 \pm 3 stretch-sensitive CBCO fibers). Table of figure $2 \mathrm{C}$ gives the number of the sensory afferents activated by sinusoidal movements imposed to 10 CBCOs. A total number of 195 extracellular spikes has been studied to determine their sensitivity to $\mathrm{CBCO}$ strand movement. $55.5 \%$ of the recorded units were release-sensitive fibers $(n=108)$ against $28 \%$ of stretch-sensitive units $(n=55)$. In both cases, most of the CBCO units coded mainly one direction of the imposed movement, their discharge lasting during a part of the opposite movement. In all experiments, some CBCO fibers $(16.5 \%$, $\mathrm{n}=32$ ) were classified in the "Non-Specific" group because their response was not clearly related to one phase of the imposed movement ( $\mathrm{R} \leq 0.3$; see Methods). Figure 3 presents a typical experiment in which different types of $\mathrm{CBCO}$ units were characterized from the $\mathrm{CBCO}$ neurogram, using the «Wave Marker » Spike2 program. The different identified extracellular 
spike templates are presented with the corresponding event histograms, which represent the occurrence of each extracellular spike in the stimulation cycle (bin size: $3 \mathrm{~ms}$ ). In this experiment, 14 distinct release-coding and five stretch-sensitive $\mathrm{CBCO}$ units could be differentiated. Nevertheless, three sensory units did not code preferentially one direction of the imposed movement $(\mathrm{R} \leq 0.3)$ All the release-sensitive fibers responded during the whole range of the release movement. Therefore, it appears that the $\mathrm{CBCO}$ coding is distributed, i.e. sensory fibers do not code an extremely specific range of the movement. The phase $(\alpha)$ of the mean of each release-sensitive unit varied between 92.3 and 152.5 degrees, which indicates some differences in the coding of the various sensory units. Moreover, although some interunit differences exist (event histogram peaks occurred between 65 and 125 degrees), most of the units fired when the velocity of the imposed movement was maximum (90 degrees).

Thus, sinusoidal movement stimulation and extracellular studies of sensory neurograms allowed us to determine how many $\mathrm{CBCO}$ afferents were excited in the angular range of the stimulation applied to the $\mathrm{CBCO}$ strand. Ramp movement stimulation during intracellular recordings from identified CBTs were used to separate position and movement sensitivities of the sensory neurons.

I B - Classification of the release-coding sensory afferents - Intracellular study.

Two groups of release-sensitive fibers were defined on the basis of their response to ramp stimulations. Some were active only during one direction of movement; this group was subdivided into two subgroups (phasic and phasico-tonic), depending upon their position sensitivity. Others displayed a continuous although modulated discharge whatever the direction of the movement. In this study, we analyzed 19 phasic and 23 phasico-tonic, from the first group, and 22 continuous firing fibers from the second group. 


\section{Phasic CBCO units.}

$\mathrm{CBCO}$ units that responded exclusively during the release movements of the $\mathrm{CBCO}$ strand (see example in Fig. 4A), and were silent during plateaus (see detail in insert), were classified as phasic units. Instantaneous frequency of this kind of sensory terminals varied from $5 \pm 3$ to $75 \pm 8 \mathrm{~Hz}$ during release movements, and mean frequency varied from $10 \pm 5$ to $50 \pm 10 \mathrm{~Hz}$. As shown by the mean frequency histogram of figure 4A example (bottom), there was no clear relationship between the mean firing frequency and the angular sector in which movement was applied. Moreover, the pattern of discharge was very variable from one cycle to the next. This explains the apparent discrepancy between the raw data (Fig. 4A, top) and the mean frequency (histogram in Fig. 4A). When low velocity $\left(0.25 \mathrm{~mm} \cdot \mathrm{s}^{-1}\right)$ ramp stimulation was applied (Fig. 4B), the mean frequency of every phasic CBTs was dramatically reduced to about one third of that obtained with high velocity $\left(1.25 \mathrm{~mm} . \mathrm{s}^{-1}\right)$ ramp stimulation.

\section{Phasico-tonic CBCO units.}

Phasico-tonic fibers (Fig. 5) were characterized by both a phasic response during release movements and a response to position. In general, the tonic response developed from a particular release position (different for each unit) and increased with the degree of release up to the maximum release position. As shown on figure $5, \mathrm{~A}$ and $\mathrm{B}$, phasico-tonic types of CBCO units can be separated into two groups depending upon the hysteresis of position coding: The first one (CBT 1, Fig. 5A) was characterized by spike emission for the most released positions, whatever the direction of the movement applied between maintained positions. However for a given position, the discharge was larger after a release movement than after a stretch movement. The second group (CBT 2, Fig. 5B) stopped firing during the 
stretching phase; even for most release position, a stretch movement induced an inhibition of tonic firing that persisted during the two seconds of maintained position. Nevertheless, firing patterns of both types (CBT 1 and 2) were similar during the $\mathrm{CBCO}$ release (see detail in insert): the high frequency phasic firing was followed by a lower frequency firing during the plateaus. Histograms of both mean frequencies, and linear regressions, showed that phasic (white histogram) and tonic (dark histogram) firings were increasing with the release of the CBCO strand. It was noticeable that in both cases the phasico-tonic units fired with a higher frequency during movements than during plateaus (up to $48 \pm 7 \mathrm{~Hz}$ during ramps against up to $12 \pm 5 \mathrm{~Hz}$ during plateaus). The velocity sensitivity of the phasico-tonic CBTs was exclusively limited to the phasic part of their response as shown by frequency histograms on figure 5C. As is the case for phasic CBCO units, when the velocity of the ramp was increased from 0.25 to $1.25 \mathrm{~mm} \cdot \mathrm{s}^{-1}$ (i.e. multiplied by 5 ) the firing frequency of the movement-sensitive component of the phasico-tonic fiber was multiplied by 3 (white histogram). By contrast, the firing frequency of the tonic component appeared to be non significantly affected by the change in velocity (dark histogram).

As figure 6 shows, the phasico-tonic $\mathrm{CBCO}$ units presented an adaptation of the tonic firing when the mechanical stimulation was stopped in a released position for a long time (> 10s, Fig. 6A). At the end of the last ramp, the tonic firing began with a frequency of $18 \pm 3$ $\mathrm{Hz}$ that was reduced to a basal value of $4 \pm 2 \mathrm{~Hz}$ within 5 seconds. Figure $6 \mathrm{~B}$ shows the mean firing frequency calculated over $5 \mathrm{~s}$ intervals (histogram) and instantaneous frequency (filled circles) plotted as a function of time, after the mechanical stimulation was stopped in the most released position (time 0), for one phasico-tonic fiber. The basal instantaneous frequency value was obtained only after six seconds in released position. 
Never described in detail in previous reports, this kind of fibers was characterized by a continuous firing (at least $10 \pm 4 \mathrm{~Hz}$ ) that was modulated by movements imposed to the CBCO strand. Nevertheless, release sensitive units presented a specificity for the release phase of the mechanical stimulation (where firing frequency could raise to a mean value of 65 $\pm 15 \mathrm{~Hz}$ during ramps). As shown on figure 7A, continuous discharge fibers fired with a higher frequency during the $\mathrm{CBCO}$ release but were still spiking during the stretch of the sensory organ. In this type of units, a movement sensitivity was also evident. The mean frequency histograms (Fig. 7B) show a marked difference between the movement response (white histogram) and the position response (dark histogram), as was the case for phasicotonic units, during the $\mathrm{CBCO}$ release. The movement coding discharge displayed a clear-cut position sensitivity: the response to the same ramp movement in the most released position reached $65 \mathrm{~Hz}$ whereas in more stretched position it was below $25 \mathrm{~Hz}$. However, the positionrelated movement sensitivity was not linear but hyperbolic. In contrast, the activity during maintained positions did not seem to be correlated to the position itself. Nevertheless, this activity was more important during the release than the stretch phase of the imposed movement. During the CBCO stretch, there was no clear difference between both types of firing (ramps or plateaus). Although these fibers were activated by release movements they did not code the velocity, neither for the movement-related firing (Fig. 7C, white histogram) nor for the maintained position activity (Fig. 7C, dark histogram).

II- Dep MN monosynaptic reflex responses.

In order to analyze the $\mathrm{MN}$ monosynaptic response, we performed intracellular recordings from the Dep MNs in high $\mathrm{Ca}^{2+}$ and high $\mathrm{Mg}^{2+}$ concentration saline. As shown in 
figure 8 (left), in a normal saline the Dep MN monosynaptic reflex response induced by CBCO mechanical stimulation was strongly masked by all the central inputs that reach the Dep MN. Perfusing the divalent cation enriched saline exclusively onto the ganglion allowed to reduce dramatically the central activities without affecting the sensory afferent informations (Fig. 8, right). In these conditions, the Dep MN monosynaptic response were unmasked and the functional relationship between the type of response of the Dep MNs, and their intrinsic properties could be analyzed.

Dep MN monosynaptic reflexes - The different resistance responses.

The reflex responses displayed by the Dep MNs are variable. If the response of the assistance Dep MN is stereotyped, i.e. EPSP bursts occurring exclusively during stretching ramps of the CBCO stimulation, the 8 resistance Dep MNs are able to display responses of different shape. Ramp movements imposed to the CBCO strand were able to produce in the resistance Dep MNs two different types of resistance responses (Fig. 9). Some Dep MNs showed a reflex response characterized by bursts of EPSPs (about 1 to $4 \mathrm{mV}$ amplitude) during the releasing ramps (Fig. 9A). These bursts of EPSPs were almost constant from the first to the last releasing movement of a stimulation cycle. This kind of response, where EPSP bursts stopped since the beginning of the plateaus (see detail in insert of Fig. 9A), was defined as a «phasic response ». The second type of reflex responses (Fig. 9B) was characterized by the same phasic bursts of EPSPs, which summated on a general depolarization of the MN that occurred during the whole release of the CBCO. In this case, the amplitude of the EPSP burst weakly increased from the first to the last releasing ramp $(1 \pm 0.4 \mathrm{mV}$ during the first ramp, and $3 \pm 0.3 \mathrm{mV}$ during the last). In parallel, the Dep MN depolarization was increasing from the beginning until the end of the $\mathrm{CBCO}$ release (from 0 to $1.7 \pm 1 \mathrm{mV}$ ). This kind of response (see detail in Fig. 9B insert) defined a «phasico-tonic » Dep MN response. As shown in figure 
9C, although the phasic bursts of EPSPs swiftly disappeared, the tonic depolarization of the phasico-tonic Dep MNs persisted (with an almost constant value) when the stimulation was stopped in a released position. The Dep MN completely repolarized only when the CBCO stretch started.

Tonic / phasic properties of MN and monosynaptic response to movement.

Since it was often claimed that phasic MN had larger diameter and higher conduction velocity, we used these parameters to classify the Dep MNs. Figure 10A presents the conduction delays of 59 Dep MNs recorded from 12 experiments. The different MNs are grouped according to the monosynaptic reflex response they displayed, i.e. assistance, phasic resistance, phasico-tonic resistance or no response. In the four cases, no correlation appeared between conduction delays and the kind of monosynaptic response. The dispersion observed in the delays in each group is quite large: from 2.35 to $10 \mathrm{~ms}$ for the no responding Dep MNs (circles); from 2.5 to $8.75 \mathrm{~ms}$ for the phasico-tonic resistance MNs (filled squares); from 2.19 to $8 \mathrm{~ms}$ for the phasic resistance MNs (white squares); and from 3.44 to $6.88 \mathrm{~ms}$ for the assistance Dep MN (stars). This dispersion of conduction delay values for the unique assistance Dep MN would indicate some variability from one animal to the other. Nevertheless, in a single experiment where all Dep MNs were recorded, the distribution of conduction delays was similar and did not point out any relation with the reflex response displayed by the different Dep MNs.

In order to classify MNs on the basis of their firing properties, we used injection of long lasting depolarizing current pulses (2s-duration, $0.3 \mathrm{~Hz}$ ). Some MNs fired continuously all along the depolarizing pulse, with a discharge frequency depending upon the amount of injected current; they are defined as tonic MNs. Other MNs fired only few spikes at the beginning of the current pulse and rapidly decreased their firing frequency. Their discharge 
stopped before the end of the pulse; they are defined as phasic MNs. It appeared that the firing pattern of the Dep MN and its reflex response were not correlated since both patterns could be recorded in Dep MNs displaying different monosynaptic reflex response (data not shown).

\section{Active membrane properties of MN and monosynaptic response to movement.}

The Dep MN V/I curves were performed in a $5 \mathrm{mV}$ range around the membrane potential in order to estimate the role of the membrane properties in the reflex response, since CBT-related EPSPs generally may reach up to $5 \mathrm{mV}$ in MNs. V/I curves, issued from injection of depolarizing and hyperpolarizing current pulses, revealed four types of electrical behavior in high divalent cation saline (Fig. 10B). Some Dep MNs (35\%) displayed almost a linear response to current injection. The majority (51\%) presented a negative rectification for negative current pulses $(\Delta \mathrm{V} 1)$ and a weak positive rectification for positive current pulses $(\Delta \mathrm{V} 2)$. A little part of Dep MNs $(8.5 \%)$ showed a double negative rectification ( $\Delta \mathrm{V} 1$ and $\Delta \mathrm{V} 2$ ). The last type of electrical behavior, a positive rectification $\Delta \mathrm{V} 1$ and a negative rectification $\Delta \mathrm{V} 2$, was detected in few cases (only $5.5 \%$ of the impaled Dep MNs). $\Delta \mathrm{V} 1$ and $\Delta \mathrm{V} 2$ values were calculated as the differences between the linear regression (around 0) and the real values for -5 and $+5 \mathrm{nA}$ injected current amplitudes.

In order to represent the rectification properties of all recorded Dep MNs in a single diagram, we plotted $\Delta \mathrm{V} 2$ as a function of $\Delta \mathrm{V} 1$ for each MN (Fig. 10C). This diagram revealed clusters of Dep MNs that would indicate distinct behavioral groups of MNs. However, each cluster contained phasic and phasico-tonic (filled squares) resistance Dep MNs, except for cluster 5 (positive $\Delta \mathrm{V} 1$ and negative $\Delta \mathrm{V} 2$ ), that contained exclusively the assistance Dep MN (stars). Non responding Dep MNs (open circles) were also found in clusters 1 and 2 (moderate negative $\Delta \mathrm{V} 1$ ), but not in clusters 3 and 4 (larger negative $\Delta \mathrm{V} 1$ ). 


\section{DISCUSSION}

In this paper, we have characterized the properties of both elements involved in the "stretch reflex" in crustacean walking legs: the CBCO sensory afferents and the connected MNs. We will discuss successively the functional aspects of the present results, the types of sensory coding and $\mathrm{MN}$ responses.

The crayfish thoracic ganglion in vitro preparation.

The crayfish thoracic walking system is dissected out in such a way to eliminate most of the sensory inputs that can excite the MNs. Only the CBCO is kept intact in the Petri dish with its sensory nerve that innervates the fifth thoracic ganglion, only leaving functional the monosynaptic reflex pathway. Perfusing the high $\mathrm{Ca}^{2+}$ and high $\mathrm{Mg}^{2+}$ saline upon the ganglion, by rising the threshold for spiking, we got sure to strongly limit the polysynaptic pathways which allowed us to study much clearly the monosynaptic connections between the CBCO sensory afferents and the MNs. Consequently high $\mathrm{Ca}^{2+}-$ high $\mathrm{Mg}^{2+}$ saline emphasized the monosynaptic MN responses (Fig. 8). In all experiments, we were very careful to have very stable conditions and reproducible responses before performing the recordings (about two hours after the onset of the dissection). The CBCO was dissected out and disposed in the Petri dish in such a position that the puller exactly imposed movements to the strand in the same way as if it was in the intact leg. The CBCO strand length was measured in the fully released position, in order to apply stretches that were one third of the original length. All stimulations were applied in this angular sector that corresponds to the angular range covered 
during the locomotor movements of the leg: The $\mathrm{CB}$ joint allows movements within the angular sector from the maximum of levation when the leg contacts the thorax, to the maximum of depression when the leg contacts the ventral carapace. Accidentally the CB joint can reach these extreme positions, for example when the animal is upside down. Nevertheless, movements involved in locomotion or in posture are restricted to about 60 degrees, between the horizontal plane and the complete levation. During levation the CBCO strand is completely relaxed, and during depression it is slightly stretched; we focused our study on this functional part of CB joint movements.

\section{Sensory unit coding.}

By the past, the crustacean walking leg chordotonal organs have been classified in two types: the first type present a symmetric discharge, as the pro-dactylopodite (PD), the carpopropodite $\left(\mathrm{CP}_{1}\right)$, the mero-carpopodite $\left(\mathrm{MC}_{1}\right)$ and the $\mathrm{CB}$ chordotonal organs, i.e. they have fairly the same number of stretch-sensitive and release-sensitive sensory units; the second type only possess release-sensitive sensory fibers, as the $\mathrm{CP}_{2}$, the $\mathrm{MC}_{2}$ and the basi-ischiopodite chordotonal organs (Mill 1976; Mill and Lowe 1973). Other chordotonal organs are not disposed at a joint: the cuticular stress detectors $\left(\mathrm{CSD}_{1}\right.$ and $\left.\mathrm{CSD}_{2}\right)$, located near the $\mathrm{CB}$ joint, are linked to a small window of soft cuticle and respond to mechanical stretching and releasing of their strand when the cuticle is stimulated (Marchand et al. 1995). In 1991, El Manira et al. described the CBCO: it is composed of 40 cells, half of them are sensitive to the stretch of the strand and the others are sensitive to its release. In this study, the analysis of the sensory coding was performed using two types of mechanical stimulations imposed to the CBCO strand.

The sinusoidal movements were used because it resembles the real movement performed by the CB joint during walking activity. Ramp movements were used to finely 
distinguish between position and velocity-sensitive components of the responses. However, ramp movements did not allow analysis from the neurogram because of the large number of units synchronized during each ramp. Therefore, ramp stimulations were exclusively performed during intracellular recordings from CBTs. By contrast, sine wave movements allowed the analysis of the neurogram because no synchronization occurred. From one experiment to the other, we were very careful to always perform ramps which had the same speed and amplitude characteristics. However, because the released CBCO length varied from 1 to $1.8 \mathrm{~mm}$, the number of ramps imposed to the strand was modified accordingly (Figs. 4 to 7). This procedure results in ramp amplitudes being different relatively to the released CBCO length. However, the results were very comparable whatever the imposed ramp amplitudes.

Our results confirm the previous observations that described the unidirectional responses of the sensory fibers (Bush 1965a, b; Mendelson 1963; Mill 1976) and, from more sophisticated tools, give new insights concerning the chordotonal organ fine sensory coding. By the past, most of the studies were performed from extracellular recordings (Bush 1965a, b; Clarac 1970), the analysis being based only upon the amplitude of the action potentials, and remained sometimes quite doubtful concerning the discrimination of very close amplitude units. Our extracellular analysis, based upon the extracellular action potential recognition, thoroughly studied the discharge of almost all the sensory units excited during movements imposed in a physiological range. Sensory terminal intracellular recordings allowed us to identify specifically different types of sensory units. They can be divided into three subtypes which are the phasic, the phasico-tonic and the continuously firing sensory fibers. This classification is mainly based upon the position sensitivity because all of them are strongly sensitive to movement. The phasic units only responded to movement, their response being unchanged whatever the angular sector where it was measured. By contrast, in both phasicotonic and continuously firing units, the response to movement was considerably affected by 
the angular sector where it was measured. Therefore, among movement-sensitive responses (dynamic responses) we can distinguish the position-unaffected dynamic (phasic units) from the position-modulated dynamic responses (phasico-tonic and continuously firing units). In addition, the dynamic response may be velocity-sensitive (phasic and phasico-tonic units) or not (continuously firing units). Surprisingly, we did not find purely position-coding units as was usually described (Bush 1965a; Clarac 1970; Matheson 1990), but all units coding positions were also activated during movements (phasico-tonic CBTs). Whatever the imposed movement (ramp or sine wave), it appeared that each sensory fiber is activated in a wide angular sector. We never recorded any fiber coding specifically for a small joint angular sector.

As a conclusion of this study, it seems that the coding of movement is shared by all the sensory fibers, i.e. on the whole angular sector of the CB joint, upward movements should activate about 20 release-sensitive fibers and downward movements should activate about 20 stretch-sensitive fibers. Moreover, during movements, the firing frequency of any CBT is always three to ten times higher than during maintained positions. Consequently, the major information conveyed by this sensory system is dynamic, and whatever the postsynaptic neurons they should be more excited during movements than during maintained positions. The CBCO movement-sensitivity may therefore be responsible for the resistance reflex being a dynamic reflex, activated by any velocity variation rather than by static positions. Concerning the coding of position, CBTs seemed to present a low selectivity because during sine wave movements all release-sensitive sensory afferents were activated on the whole range of the releasing movement. However, their maximum of discharge occurred at angular positions that were different from one CBT to the other (Fig. 3).

In the angular sector where movements were imposed to the $\mathrm{CBCO}$ strand, the releasesensitive sensory units were activated in a greater number than stretch-sensitive ones (almost 
twice the number of stretch-sensitive units). Then, in the angular sector involved in locomotion and posture, the monosynaptic pathway excites much more the Dep MNs than the Lev ones. Thus the resulting monosynaptic reflex effect is the body upholding.

\section{Monosynaptic motoneuronal responses.}

Recently, different studies upon the crustacean MNs have demonstrated that, in the thorax, the abdomen or the stomatogastric ganglia, motoneuronal pools are quite complex and not homogenous. Their intrinsic properties and their connections have been described to be responsible for this heterogeneity (Harris-Warrick et al. 1992; Le Ray and Cattaert 1997; Skorupski et al. 1992; Wine 1984). In the same MN pool, it seems that not all the MNs have the same role: Skorupski et al. (1992) demonstrated that two groups must be considered in the promotor $\mathrm{MN}$ pool, one involved in the resistance reflex and the second in the assistant pathway. More recently, Le Ray and Cattaert (1997) showed in the Dep MN pool the existence of one assistance-specialized Dep MN. In this study, we classified the Dep MNs according to their monosynaptic reflex response and their intrinsic properties. We did not take into account the electrotonic coupling that have been described to be very weak between Dep MNs (Chrachri and Clarac 1989). Classically MNs have been classified into tonic and phasic depending upon the type of muscle fibers they innervate and their activity (Kennedy and Takeda 1965a, b). Tonic MNs display continuous discharge whereas phasic MNs are activated only during rapid movements (Kennedy and Davis 1977). Generally, phasic MNs have cell bodies and axon diameters larger than tonic ones, and they convey spikes more rapidly. Functionally the resistance reflex is acting during posture and should involve preferentially postural MNs, i.e. tonic MNs. In the present work, Dep MN classification was not related neither to the muscle fibers innervated, nor to their activity in motor behavior. However, we attempted to classify Dep MNs according to their conduction velocity (Fig. 10A) and their 
firing pattern. Surprisingly this study demonstrates that this classification did not match the different types of reflex responses because resistance reflex Dep MNs were found in the whole range of the conduction delays (Fig. 10A). However this lack of correlation could be explained by the conduction delays not being representative of tonic or phasic behavior of a given MN. Concerning the three MNs which are not directly connected by the CBCO sensory afferents, they were also found in the whole range of Dep MN conduction delays (Fig. 10A). Nevertheless, this group may also be heterogeneous, some of them being excited through one or several interneurons and other not. Moreover the properties of interneurons involved in polysynaptic pathways may be very different from one MN to the other. Such an organization has already been demonstrated in the case of the insect locomotor system (Burrows and Pflügers 1988; Sauer et al. 1995) and in the case of the crayfish reflex pathways (Clarac et al. 1991), and might be very important in the reflex modulation.

In opposition, the classification of Dep MNs according to their membrane electrical properties (rectification) points out the assistance Dep MN specific positive rectification for hyperpolarizing currents (Fig. 10, B and C). In these experiments, sensory EPSP amplitudes were smaller than $5 \mathrm{mV}$ (Fig. 9); we therefore limited the exploration of the rectifying properties of $\mathrm{MNs}$ to a $10 \mathrm{mV}$ range around the resting membrane potential in order to analyze the functional effect of the reflex response onto neuron behavior (phasico-tonic responses could have involved slow active properties whereas phasic responses would not). The results of the present analysis demonstrate that this is not the case. Nevertheless, this classification shows that Dep MNs are grouped into clusters, which reveals clear-cut heterogeneity in the Dep MN pool (Fig. 10C). However, this clear-cut classification of Dep MNs does not match the type of monosynaptic reflex response anymore.

In conclusion, Dep MN properties failed to explain the differences existing between Dep MN responses. The origin of such differences should therefore be searched in the 
combination of the sensory afferent types that innervate a given MN. Such an analysis is presented in an associate study, in which the properties of monosynaptic connections between the $\mathrm{CBCO}$ sensory afferents and the nine Dep MNs that express a reflex response to $\mathrm{CBCO}$ movements are considered. 


\section{REFERENCES}

Barnes, W. J. P., And Gladden, M. H., eds. Feedback and Motor Control in Invertebrates and Vertebrates. London, Croom Helm, 1985.

BÄSSLER, U. Reversal of a reflex to a single motoneuron in the stick insect Carausius morosus. Biol. Cybern. 24: 47-49, 1976.

BÄSSLER, U. The femur tibia control system of stick insects. A model system for the study of the neural basis of joint control. Brain Res. Rev. 18: 207-226, 1993.

BerRy, M. S., AND Pentreath, V. W. Criteria for distinguishing between monosynaptic and polysynaptic transmission. Brain Res. 105: 1-20, 1976.

BURRows, M. Monosynaptic connections between wing stretch receptors and flight motoneurones of the locust. J. Exp. Biol. 62: 189-219, 1975.

BuRrows, M. Local circuits for the control of leg movements in an insect. Trends Neurosci. 15: 226-232, 1992.

Burrows, M., AND PflÜGERS, H. J. Positive feedback loops from proprioceptors involved in leg movements of the locust. J. Comp. Physiol. 163: 425-440, 1988.

BÜSCHGES, A., AND SCHMITZ, J. Non-spiking pathways antagonize the resistance reflex in the thoraco-coxal joint of stick insect. J. Neurobiol. 22(3): 225-237, 1991. 
BÜSCHGES, A., AND WOLF, H. Nonspiking local interneurons in insect leg motor control. I. Common layout and species-specific response properties of femur-tibia joint control pathways in stick insect and locust. J. Neurophysiol. 73: 1843-1860, 1995.

Bush, B. M. H. Proprioceptive reflexes in the legs of Carcinus maenas L. J. Exp. Biol. 39: 89$105,1992$.

Bush, B. M. H. Proprioception by the coxo-basal chordotonal organs, CB, in legs of the crab, Carcinus maenas. J. Exp. Biol. 42: 285-297, 1965a.

Bush, B. M. H. Leg reflexes from chordotonal organs in the crab, Carcinus maenas. Comp. Biochem. Physiol. 15: 567-587, 1965 b.

Bush, B. M. H., AND Laverack, M. S. Mechanoreception. In : The biology of crustacea edited by H. Atwood and D. L. Sandeman. New-York, Academic Press, 1982, p. 397-467.

Chrachri, A., AND Clarac, F. Synaptic connections between motor neurons and interneurons in the fourth thoracic ganglion of the crayfish, Procambarus clarkii. J. Neurophysiol. 62: 1237-1250, 1989.

Clarac, F. Fonctions proprioceptives au niveau de la région basi-ischio-méropodite chez Astacus leptodactylus. Z. vergl. Physiologie 68: 1-24, 1970. 
ClaraC, F. Motor coordination in crustacean limbs. In: Identified neurons and behavior of arthropods edited by G. Hoyle, 1977, p. 167-186.

ClaRAC, F. How do sensory and motor signals interact during locomotion. In : Motor control: concepts and issues edited by D. R. Humphrey and H. J. Freund New-York, Wiley, 1991, p. 199-201.

Clarac, F., Chrachri, A., AND CATtaert, D. Interneuronal control of a walking leg reflex in an in vitro crayfish preparation. In : Locomotor neural mechanism in arthropods and vertebrates edited by D. M. Armstrong and B. M. H. Bush. Manchester and New York, Manchester University Press, 1991, p. 33-50.

DI CAPRIO, R., AND CLARAC, F. Reversal of a walking leg reflex elicited by a muscle receptor. J. Exp. Biol. 90: 197-203, 1981.

DuYSENS, J., AND TAX T. Interlimb reflexes during gait in cat and human. In : Interlimb coordination edited by S. Swinen, H. Heuer, J. Massion, and P. Casaer. San Diego, Ac. Press, 1994, p. $97-126$.

El Manira, A., Cattaert, D., And ClaraC, F. Monosynaptic connections mediate resistance reflex in crayfish (Procambarus clarkii) walking legs. J. Comp. Physiol. 168: 337-349, 1991.

GRANIT, R. Receptors and sensory perception. New Haven, Connecticut, Yale University Press, 1955. 
Harris-Warrick, M., Marder, E., Selverston, A. I., And Moulins, M. Dynamic biological networks: The stomatogastric nervous system. MIT press, Cambridge, Massachusetts, 1992.

KEnNEDY, D;, AND DAVIS, W. J. The organization of invertebrate nervous systems. In: Handbook of Physiology, section 1, vol. 1, part 2 edited by E. R. Kandel, Bethesda, Amer. Physiol. Soc., 1977, p. 1023-1087.

KenNedy, D;, AND TAKEDA, K. Reflex control of abdominal flexor muscles in the crayfish. I. the twitch system. J. Exp. Biol. 43: 211-227, 1965a.

KENNEDY, D;, AND TAKEDA, K. Reflex control of abdominal flexor muscles in the crayfish. II. the tonic system. J. Exp. Biol. 43: 229-246, 1965 b.

LE RAy, D., AND CATTAert, D. Neural Mechanisms of reflex reversal in coxo-basipodite depressor motor neurons of the crayfish. J. Neurophysiol., in press, 1997.

Marchand, A., Liebrock, C., Auriac, M. C., Barnes, W. J. P., And Clarac F. Morphology, Physiology and in vivo activity of cuticular stress detector afferents in crayfish. J. Comp. Physiol. A 176: 409-424, 1995.

MAtHESON, T. Responses and locations of neurones in the locust metathoracic femoral organ. J. Comp. Physiol. A 166: 915-927, 1990. 
MENDELSON, M. Some factors in the activation of crab movement receptors. J. Exp. Biol. 40: 157-169, 1963.

Mill, P. J., AND Lowe, D. A. The fine structure of the PD proprioceptor of Cancer pagarus. I. The receptor stand and the movement sensitive cells. Proc. R. Soc. London B184: 179-197, 1973.

MiLL, P. J. Chordotonal organs of Crustacean appendages. In : MILL P.J. (Ed.), Structures and function of proprioceptors in the invertebrates. Edited by Chapman and Hall London, 1976, p. 243-297.

PeARson, K. G. Common principles of motor control in vertebrates and invertebrates. Ann. Rev. Neurosci. 16: 265-297, 1993.

PRINGLE, J. W. S. Proprioception in arthropods. In: The cell and the organism edited by J. A. Ramsay and V. B. Wigglesworth, Cambridge University Press, 1961, p. 256-282.

SAuer, A. E., DriesAng, R. B., BÜSChGeS, A., AND BÄSSLER, U. Information processing in the femur-tibia control loop of stick insects. 1. The response characteristics of two nonspiking interneurons result from parallel excitatory and inhibitory inputs. J. Comp. Physiol. A 177: 145-158, 1995.

SKORUPSKI, P., RAWAT, B. M., AND Bush, B. M. H. Heterogeneity and central modulation of feedback reflexes in crayfish motor pool. J. Neurophysiol. 67: 648-663, 1992. 
SkORUPSKI, P., AND SiLlar, K. T. Phase-dependent reversal of reflexes mediated by the thoracico-coxal muscle receptor organ in the crayfish, Pacifastacus leniusculus. J. Neurophysiol. 55: 689-695, 1986.

VEDEL, J. P., AND ClARAC, F. Combined reflex action by several proprioceptive inputs in the rock lobster walking legs. J. Comp. Physiol. 130: 251-258, 1979.

WHITEAR, M. The fine structure of crustacean proprioceptor. I. The chordotonal organs in the legs of the shore crab, Carcinus maenas. Phil. Trans. Roy. Soc. London B245: 291-325, 1962.

WiERsma, C. A. G. Movement receptors in decapod crustacea. J. Mar. Biol. Ass. U. K. 38: 143-152, 1959.

WINE, J. J. The structural basis of an innate behavioural pattern. J. Exp. Biol. 112: 283-319, 1984. 


\section{LEGENDS}

Fig. 1: Diagram of the experimental arrangement used in the analysis of sensory-motor activities. A: The in vitro preparation of the crayfish walking system consisted in the last three thoracic ganglia, and the nerves that innervate the two proximal joints of the left fifth leg. We kept also intact the sensory chordotonal organ $(\mathrm{CBCO})$ that encodes the vertical movements of the leg. A mechanical puller allowed us to reproduce physiological stimulations to the CBCO strand, mimicking the vertical movements of the leg. Large dots indicate the location of en passant electrodes onto the depressor nerve (Dep n) and the CBCO sensory nerve (CB n). B: Intracellular microelectrodes within the neuropile were used to record from a sensory terminal (CBT) and a Dep motor neuron (Dep MN). C: Sine wave movements imposed to the CBCO strand induced sensory activity recorded from both the CBCO nerve and a CBT. D: The same movement elicited a resistance reflex recorded from a Dep MN.

Fig. 2: Extracellular study - Methodology.

A: Procedure used to analyze the different sensory units extracellularly recorded from the CBCO nerve. In this illustration, three units were identified by their shape and amplitude. The activity of each unit was then represented using circular statistics. Within the stimulation cycle, each occurrence of the unit (unit 1 in the example) was represented by an unit vector $\left(\vec{v}_{i}\right)$. The vectorial sum of these unit vectors was calculated over several cycles and divided by the number $\mathrm{n}$ of occurrences; the resulting vector $(\vec{R})$ indicated the coding characteristics (angle $\alpha$ and vector length $\mathrm{R}$ ) of the unit (see text for details). B: Bimodal distribution of resulting vector lengths, calculated from all analyzed CBCO units. This distribution was used to distinguish between specific $(\mathrm{R}>0.3)$ and non-specific $(\mathrm{R} \leq 0.3) \mathrm{CBCO}$ units. $\mathrm{C}$ : Using the 
calculated $\alpha$ and $\mathrm{R}$ values, $\mathrm{CBCO}$ units were classified in 10 different experiments: in the angular sector we studied, most of the release-sensitive fibers were activated. Stretch-sensitive units were generally, and non-specific units were always activated in a lower ratio.

Fig. 3: Characterization of the CBCO units recruited by sinusoidal stimulation.

During sine wave stimulation applied to the $\mathrm{CBCO}$ strand, the activity of 19 distinct sensory units was analyzed. For each unit, event distribution histogram was calculated over twelve cycles. The movement cycle is drawn at the bottom of each column (scale bar: 1s). On the right of each histogram, the corresponding unit profile is shown (scale bar: $2.5 \mathrm{~ms}$ ). Below each histogram, the calculated $\alpha$ and $\mathrm{R}$ values are reported.

Fig. 4: The phasic release-sensitive CBTs.

A: Phasic CBTs were characterized by spike bursts occurring only during release ramps. As shown in insert, their firing stopped since the plateaus started. The mean firing frequency calculated over nine stimulation cycles for each ramp is presented below, and demonstrate that the position of the leg did not affect the firing frequency of this phasic CBT. B: Mean firing frequencies from all individual release ramps over the nine cycles were calculated for 0.25 and $1.25 \mathrm{~mm} / \mathrm{s}$ ramp velocities. The phasic coding of this CBT was highly velocity-dependent, because a fivefold ramp velocity increase leaded to a threefold firing mean frequency increase ( $p<0.001)$. Error bars: S.E.M.

Fig. 5: The phasico-tonic release-sensitive CBTs.

Phasico-tonic CBTs present a phasic firing, during release ramps, and develop a tonic discharge for the most released position of the CBCO strand. A: The first type of phasicotonic CBTs continued to produce spikes even after the beginning of the $\mathrm{CBCO}$ stretch. B: The 
second type stopped since the stretch started. A and B, mean firing frequency histograms (same disposition as in Fig. 4A): both phasic (white bars) and tonic (filled bars) codings were dependent on the position of the leg. Regression lines are drawn for each histogram during the release phase (correlation coefficient are in A: 0.99 for the phasic component, 0.96 for the tonic component; in B: 0.97 for the phasic component, 0.93 for the tonic component). C: Same calculation as in Fig. 4B, for both phasic and tonic components. Only the phasic pattern (white histogram) was velocity-dependent $(\mathrm{p}<0.001)$ while the tonic discharge (filled histogram) was not significantly affected by the ramp speed rising. Error bars: S.E.M.

Fig. 6: The phasico-tonic CBTs present a fast adaptation.

A: When the movement is hold in released position, the firing frequency of the CBT (raw data) quickly reduces to minimum value. B: Plot of the instantaneous frequency (dots) and of the mean frequency (white bars), corresponding to the recording in A. The basal spiking frequency (about $2.5 \mathrm{~Hz}$ ) is reached within $5 \mathrm{~s}$ after the maintained released position. Error bars: S.E.M.

Fig. 7: The continuously firing release-sensitive CBTs.

A: During the application of a ramp stimulation to the $\mathrm{CBCO}$ strand, some CBTs always responded by at least a minimal spike emission, but emitted much more spikes during the release phase of the stimulation. As it is illustrated by the mean frequency histogram (same disposition as in Fig. 4A), the continuously firing CBT presents also a clear movementsensitivity (white bars) and a very weaker purely tonic activity (filled bars). The line represents the hyperbolic correlation between the phasic component mean frequency and the position of the leg $(r=0.96)$. During the CBCO stretch, only a basal firing persisted. B: Same 
disposition as in Fig. 5C. Neither the phasic component (left) nor the tonic discharge (right) were velocity-dependent.

Fig. 8: Effect of high $\mathrm{Ca} 2+-$ high $\mathrm{Mg} 2+$ saline upon reflex activity.

In normal saline (left), the Dep MN (intracellular recording) is subjected to a lot of central inputs that mask the purely monosynaptic influences. By perfusing high $\mathrm{Ca} 2+-$ high $\mathrm{Mg} 2+$ saline (right), the central activity threshold is increased, which dramatically reduces the inputs that reach Dep MNs and allows to unmask the CBCO direct excitation. a Lev and p Lev: extracellular recordings from the anterior and posterior levator nerves.

Fig. 9: Monosynaptic resistance Dep MN responses.

Resistance Dep MNs displayed two types of monosynaptic response to CBCO release. A: Some only responded with phasic bursts of EPSPs occurring during the release ramps (detail in insert). B: Others displayed an increasing tonic depolarization of their membrane potential on which the phasic EPSP bursts summated (detail in insert). C: The tonic component of the resistance response persisted when the $\mathrm{CBCO}$ was kept released, and disappeared since the first stretching movement.

Fig. 10: Dep MN properties and reflex responses.

A: Column scatter of conduction velocities of Dep MNs with respect to their monosynaptic reflex responses. B: Four types of V/I curves observed in Dep MNs: a linear behavior, a double negative rectification, or a simple negative rectification for hyperpolarizing () or depolarizing $(\Delta \mathrm{V} 2)$ currents (see details in the text). C: Plotting of $\Delta \mathrm{V} 2$ against $\Delta \mathrm{V} 1$ for 37 Dep MNs. The distribution is not homogeneous but the Dep MNs are grouped in five clusters. 
Only the assistance responding Dep MN presented particular active electrical properties (cluster 5). 

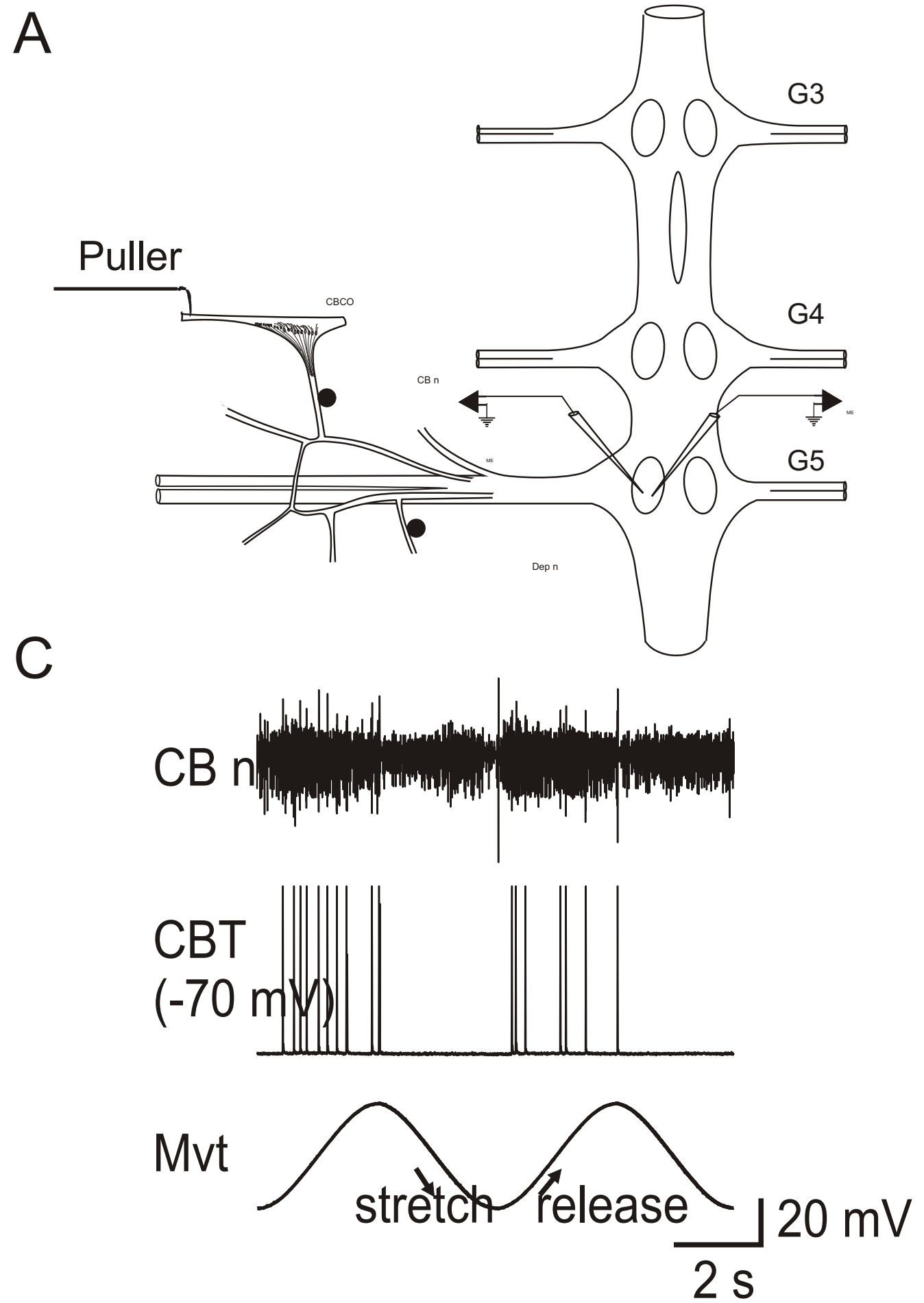

B

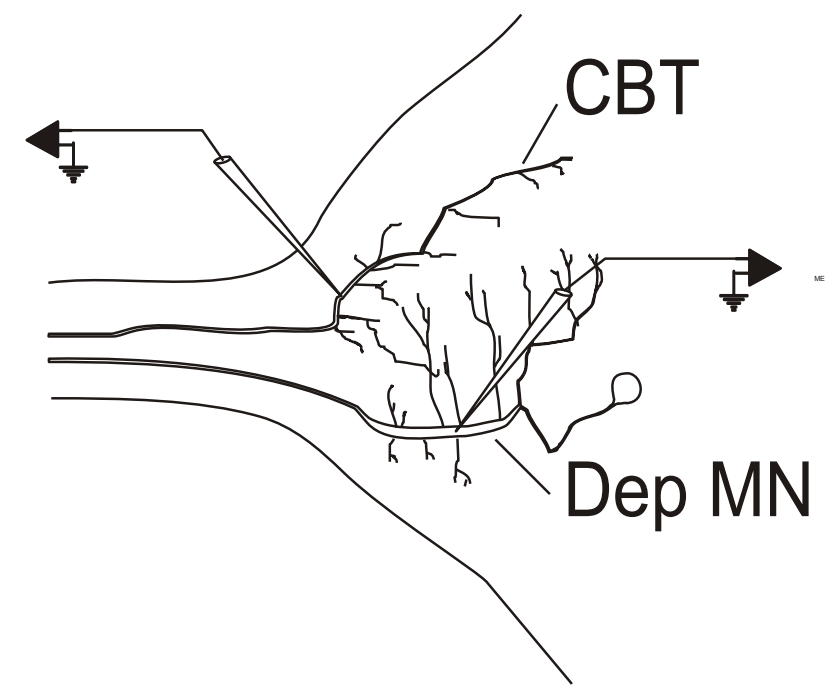

D

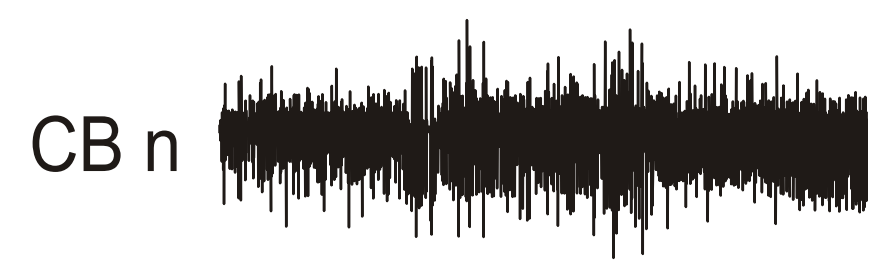

Mvt

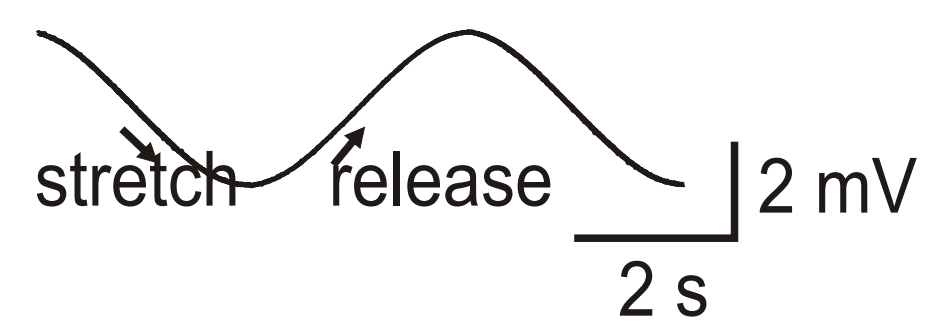


A
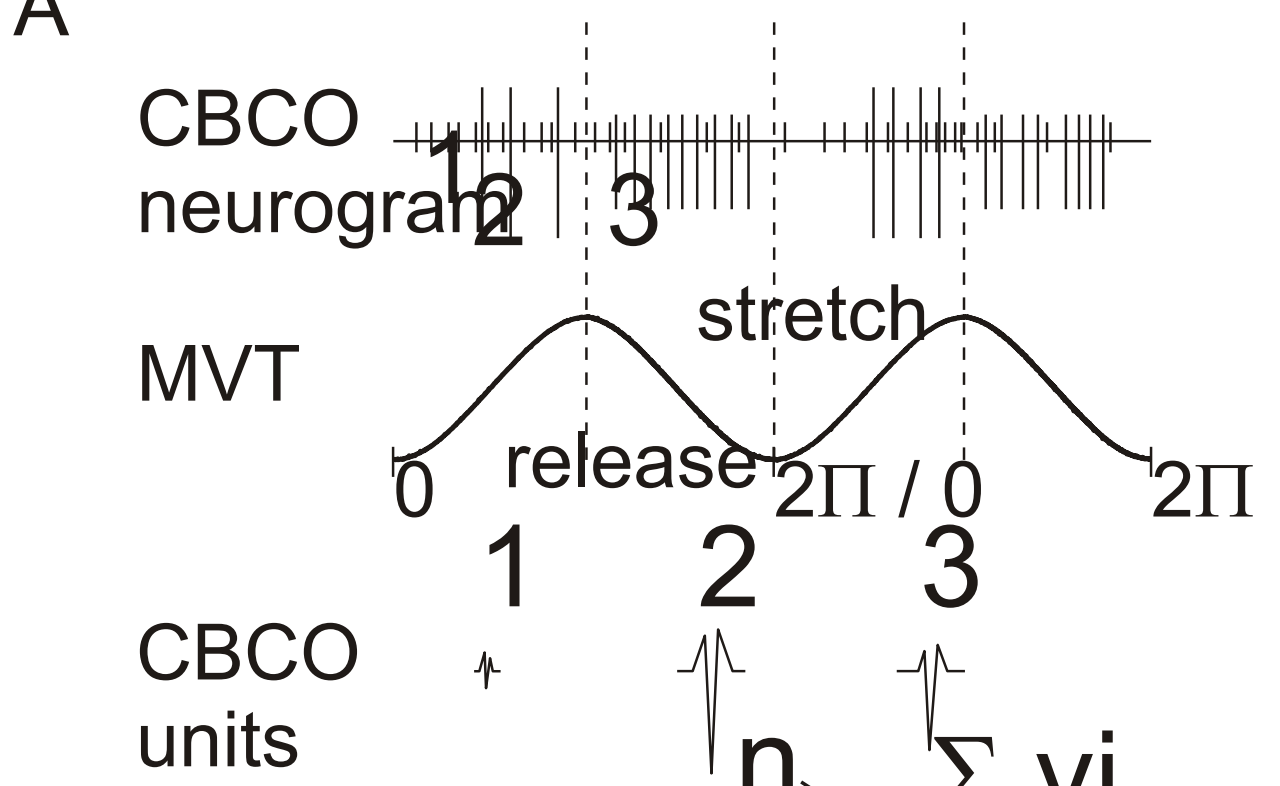

B

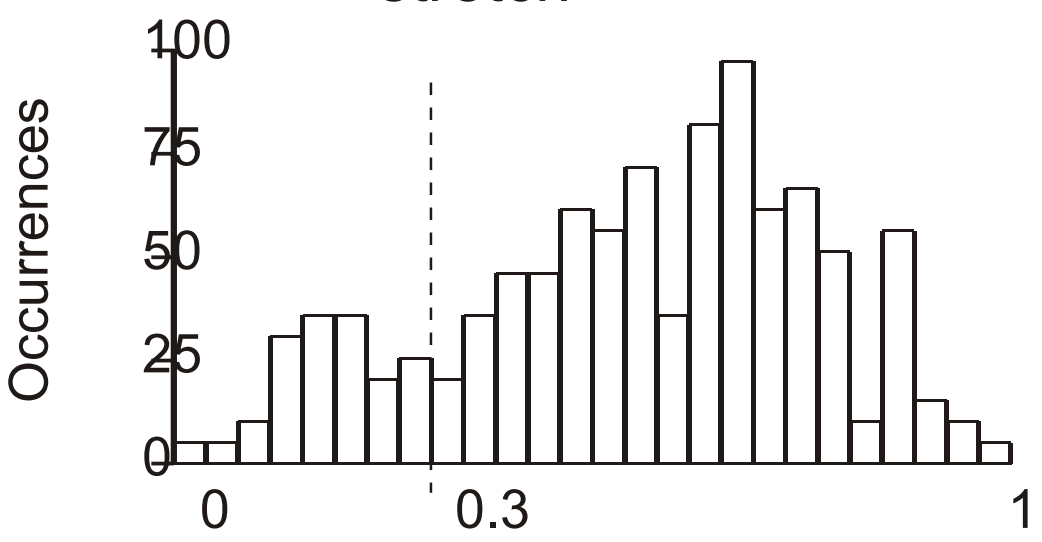

C $R$ values

\begin{tabular}{|c|c|c|c|c|c|c|c|}
\hline Expe & $\begin{array}{r}\text { Rele } \\
\text { rimentens }\end{array}$ & $\begin{array}{l}\text { gse } \\
\text { tive }\end{array}$ & $\begin{array}{l}\text { Non } \\
\text { specif }\end{array}$ & fic & $\begin{array}{l}\text { Stret } \\
\text { sensi }\end{array}$ & itive & $\begin{array}{l}\text { Total } \\
\text { numb }\end{array}$ \\
\hline 1 & 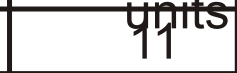 & & प्रुnts & & पytits & & 17 \\
\hline 2 & 10 & & 5 & & 4 & & 19 \\
\hline 3 & 12 & & 3 & & 4 & & 19 \\
\hline 4 & 10 & & 2 & & 4 & & 16 \\
\hline 5 & 10 & & 6 & & 10 & & 26 \\
\hline 6 & 13 & & 4 & & 3 & & 20 \\
\hline 7 & 9 & & 4 & & 3 & & 16 \\
\hline 8 & 11 & & 1 & & 1 & & 13 \\
\hline 9 & 11 & & 2 & & 12 & & 25 \\
\hline 10 & 11 & & 2 & & 11 & & 24 \\
\hline
\end{tabular}




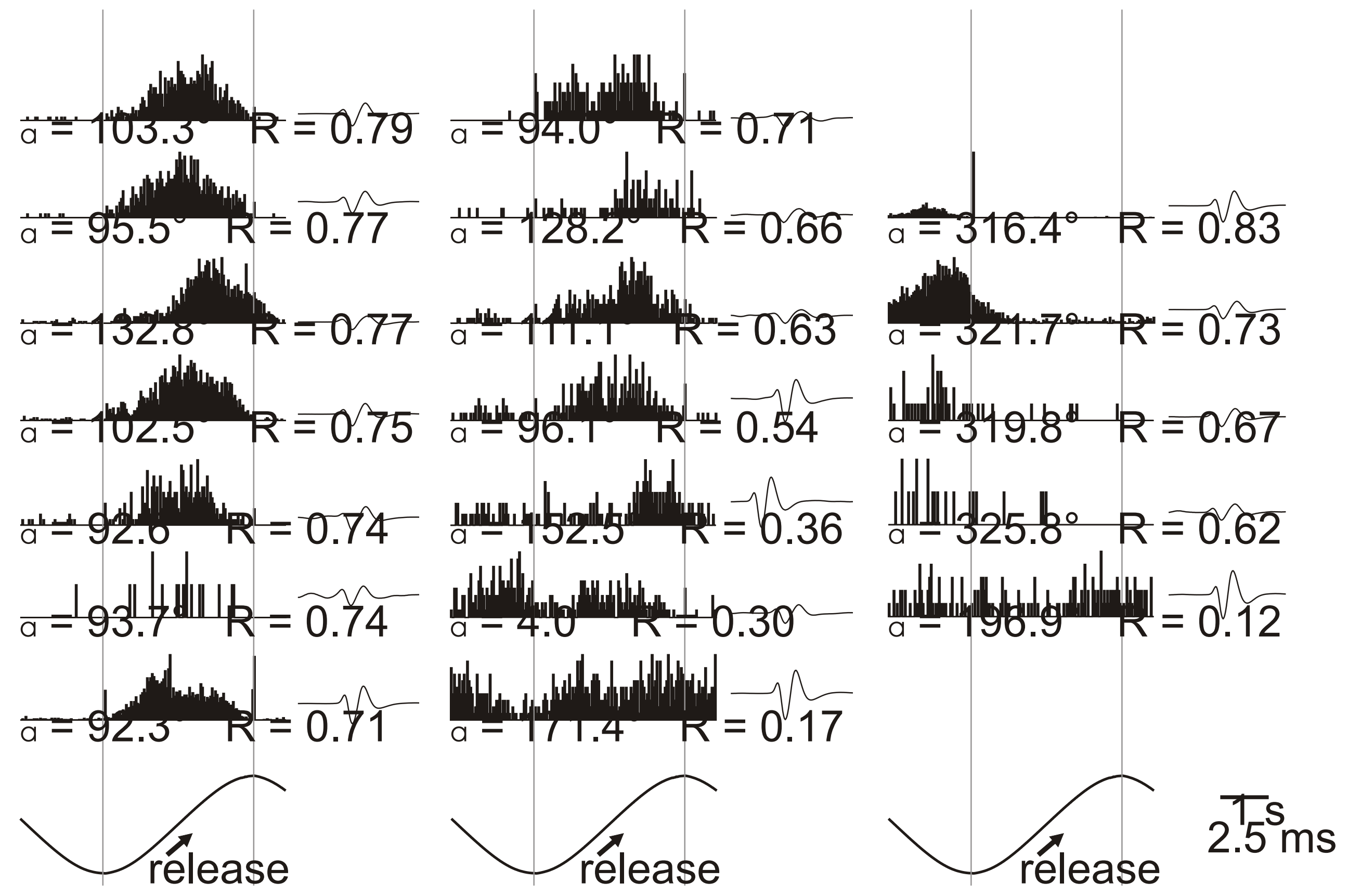


A

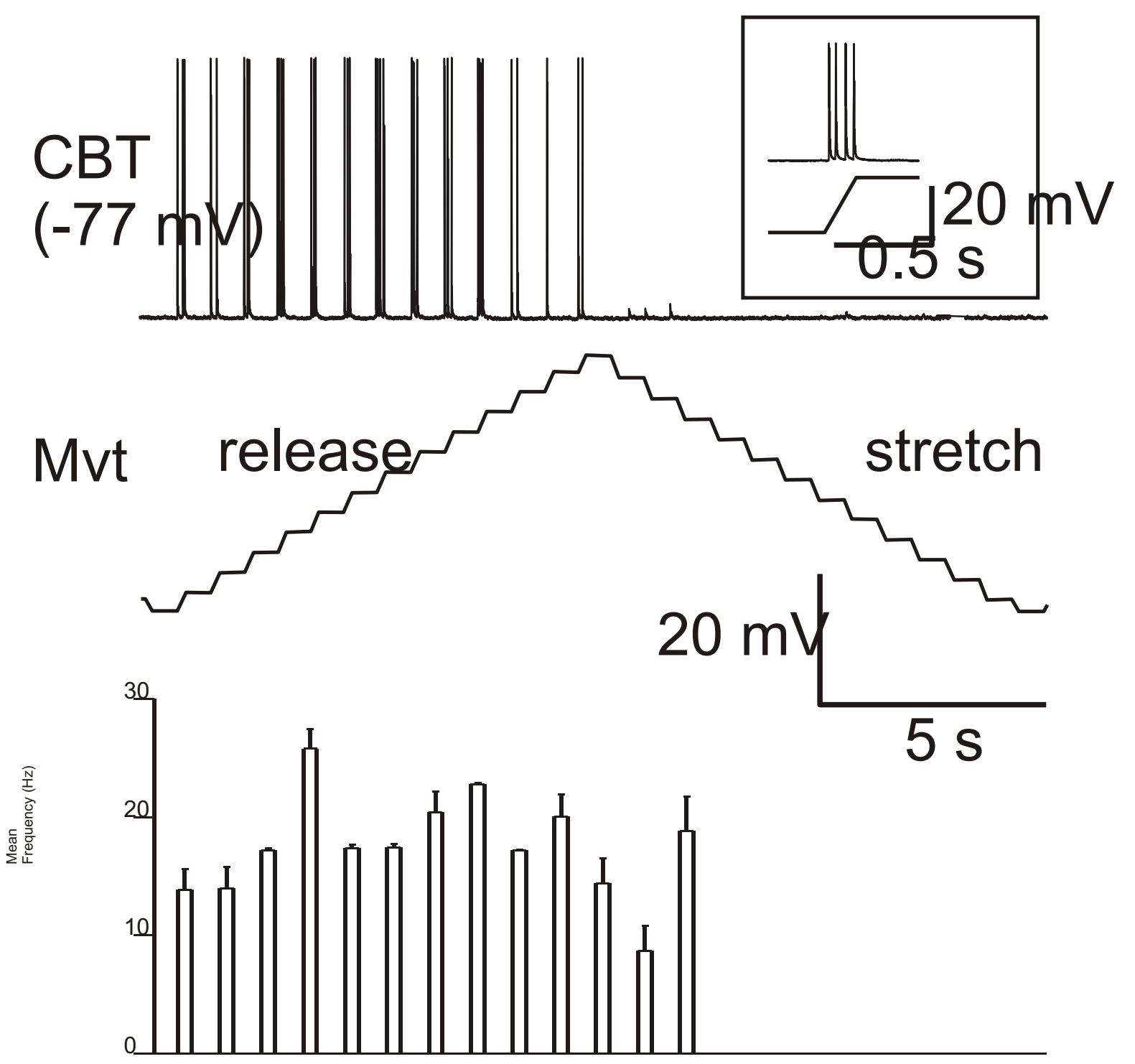

B

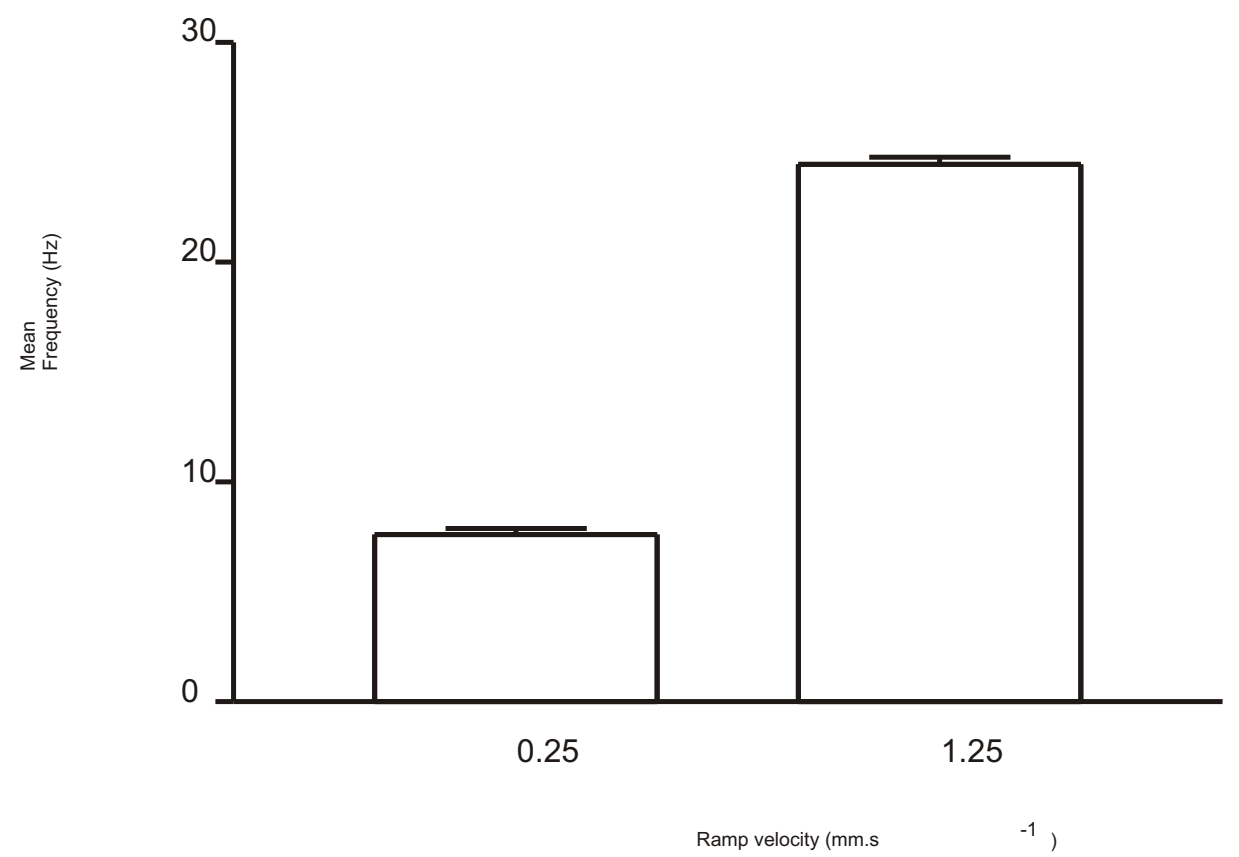


A
CBT 1 (-73 mV)

Mvt release stretch

Mean ${ }_{21}$ Frequency $(\mathrm{Hz})$

B
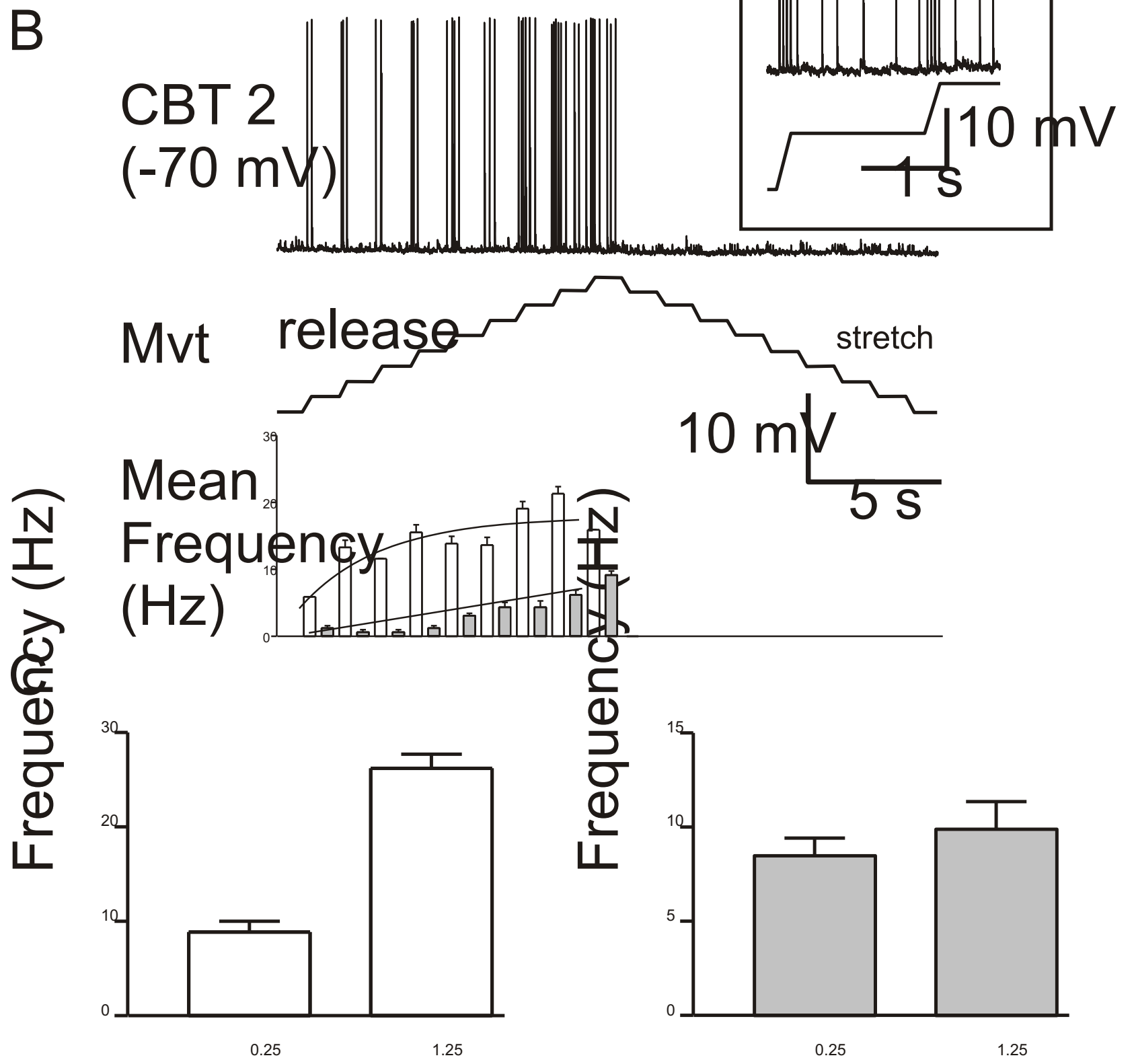
A
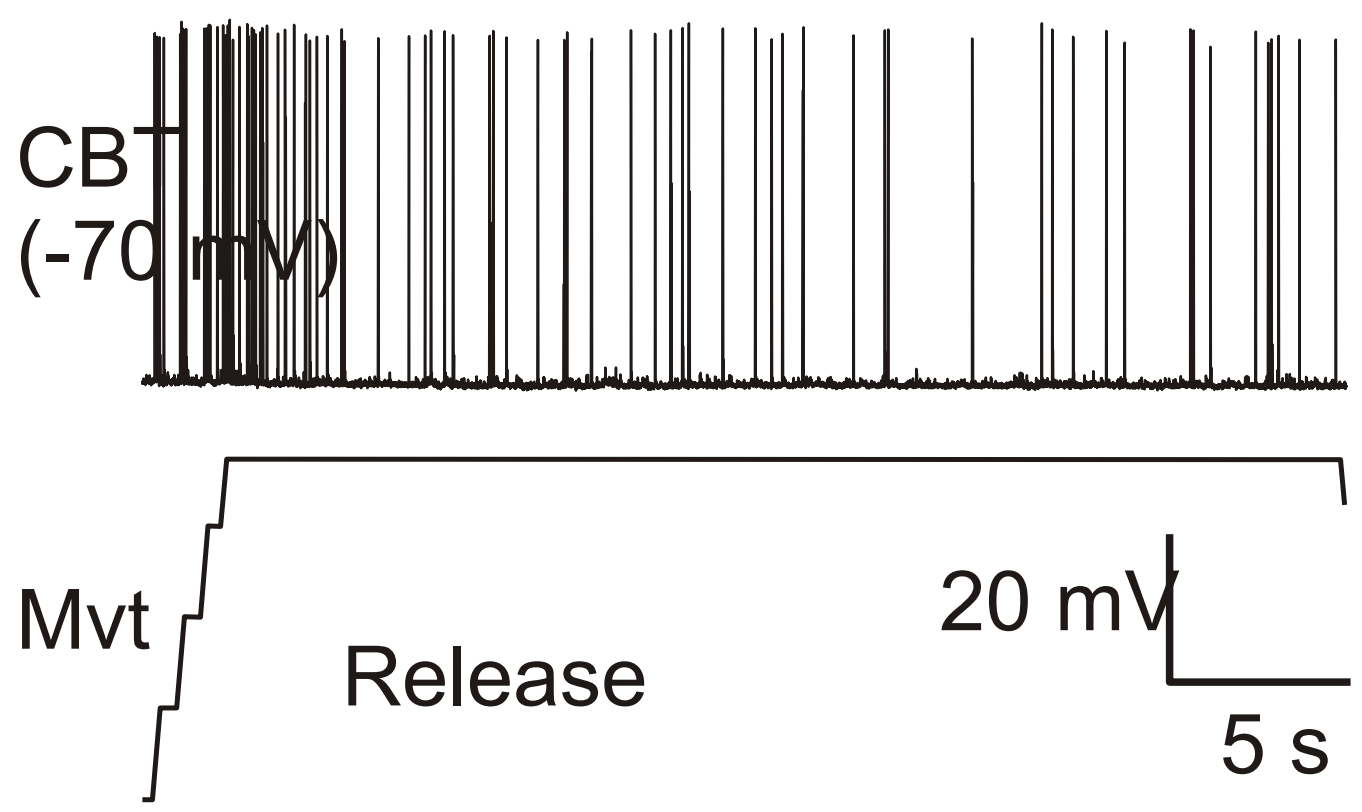

B

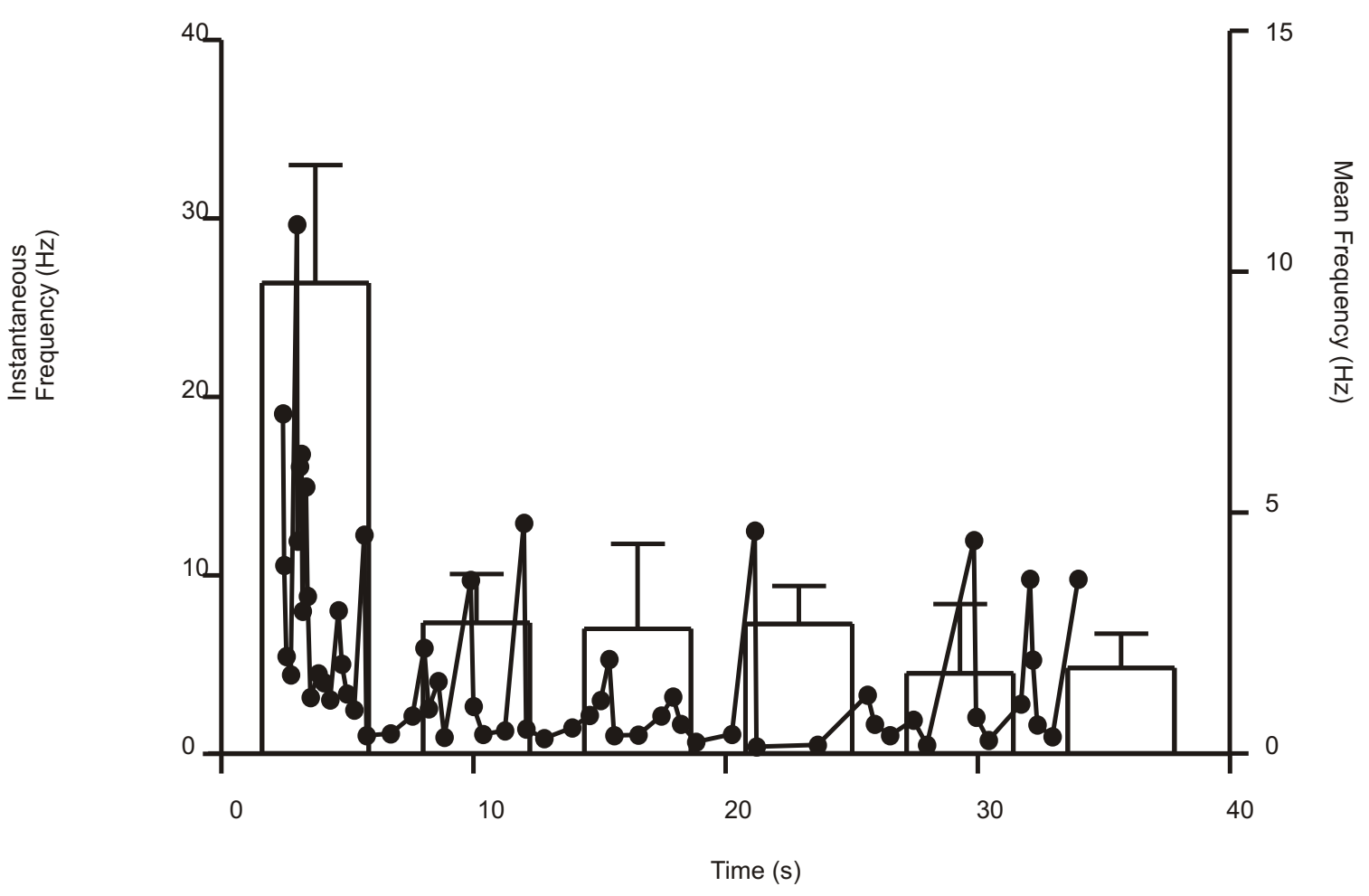


A
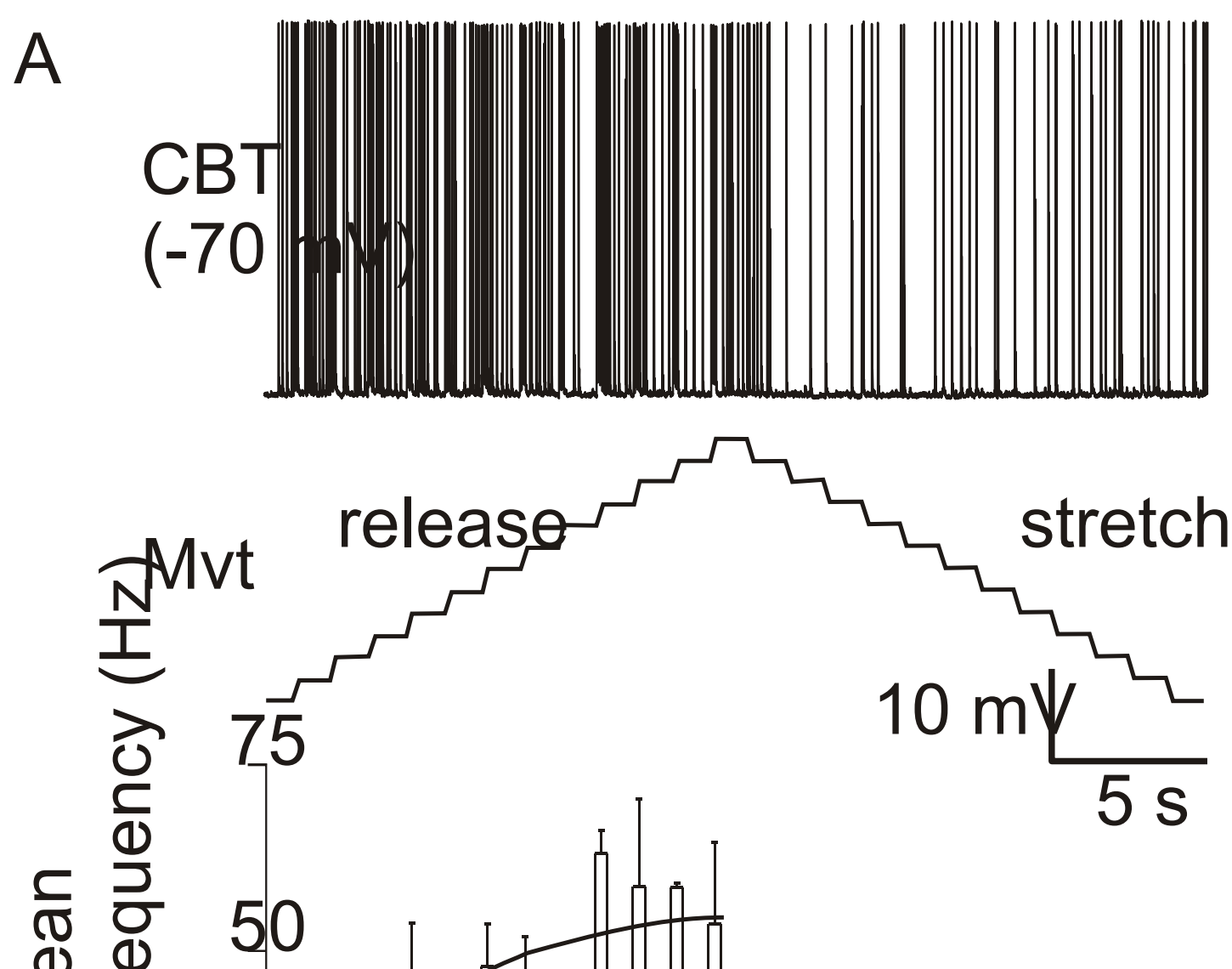

$\sum^{\infty} \frac{\mathbb{d}}{4}$

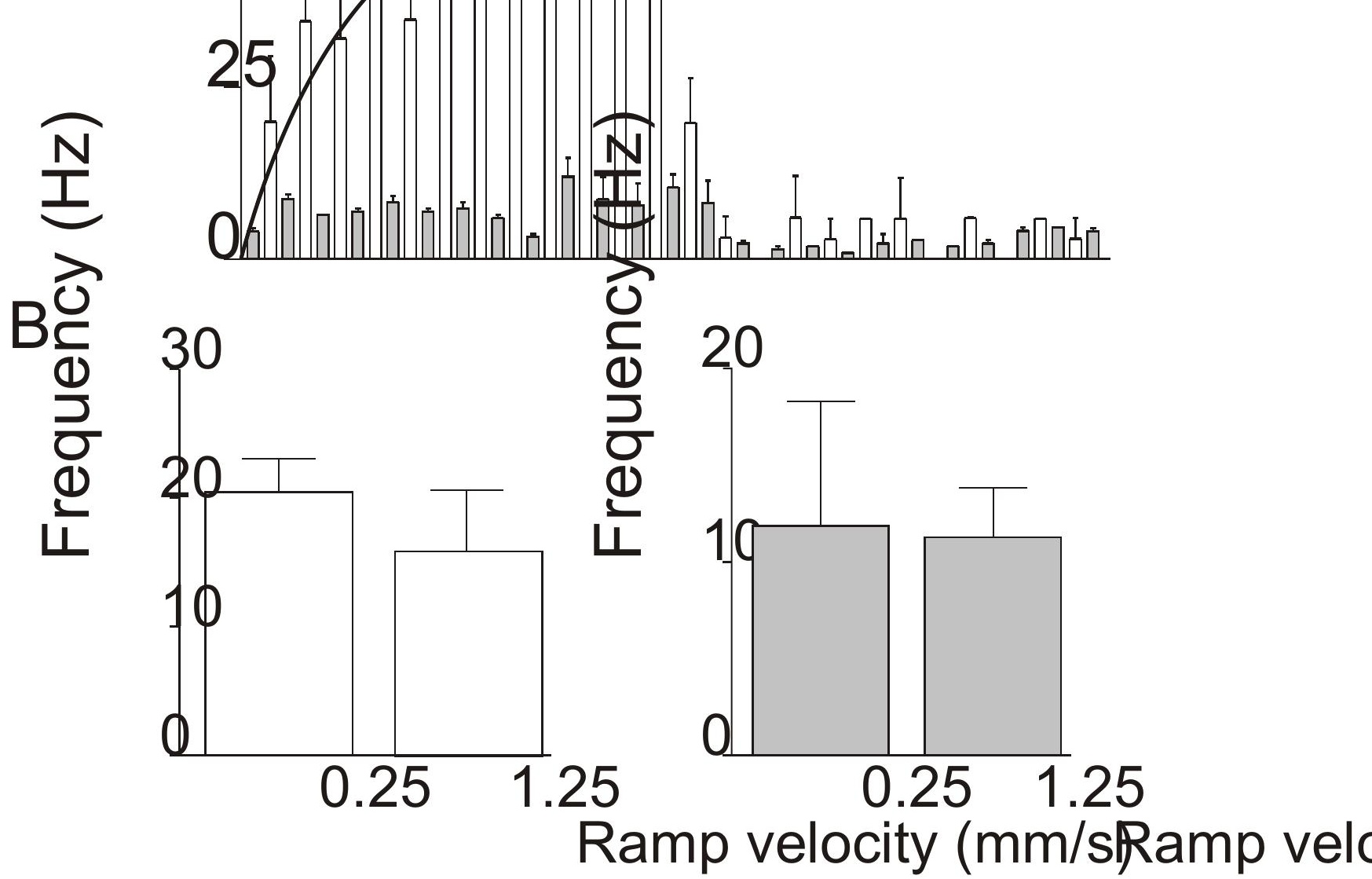


"II.

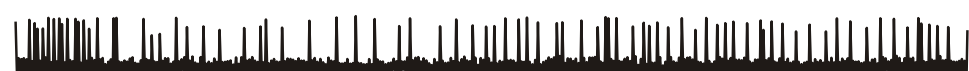

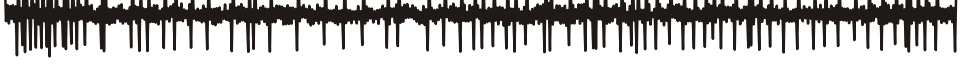

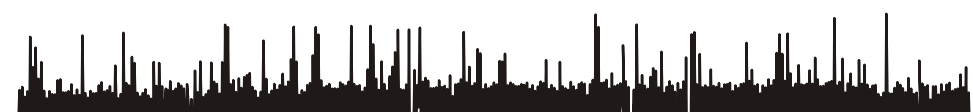
|

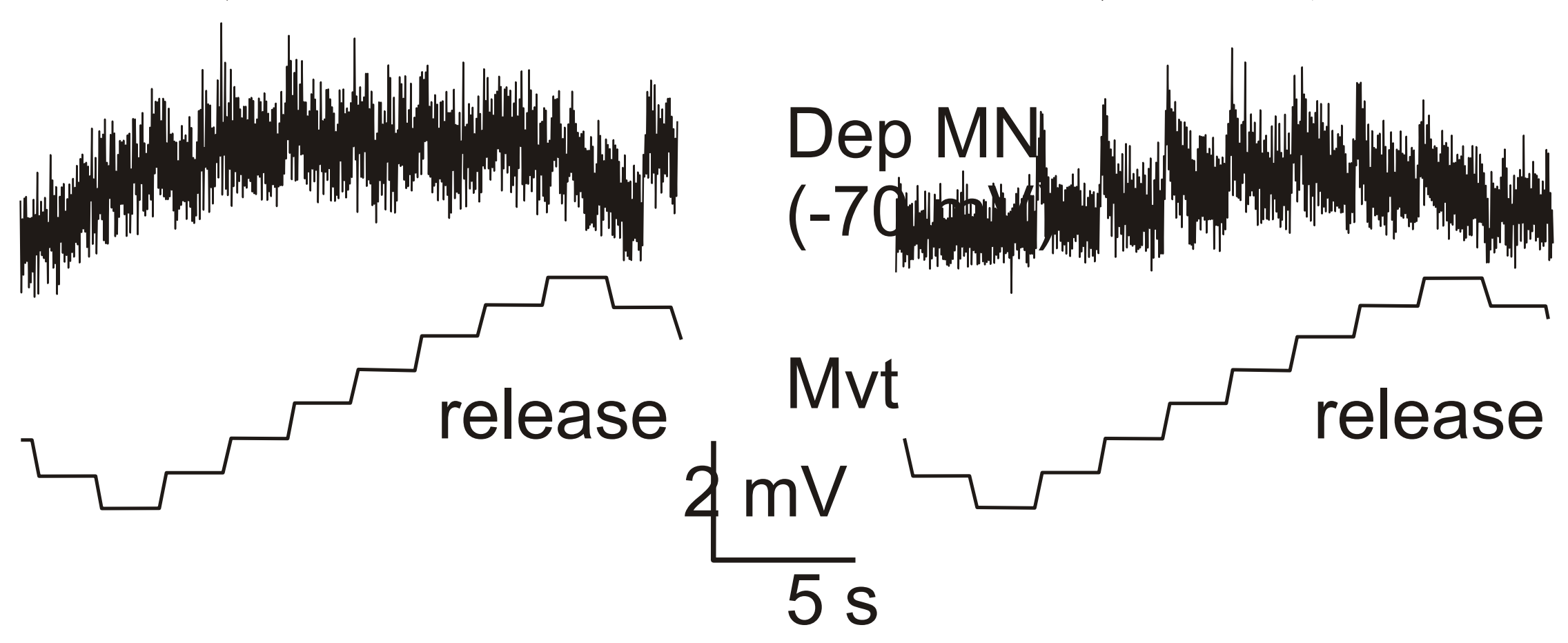

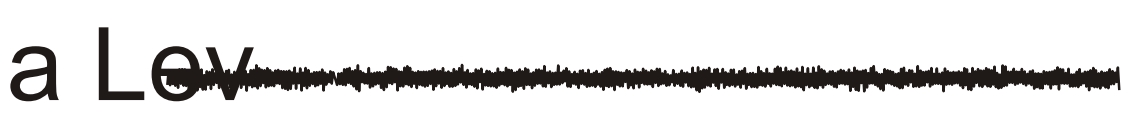

p LeV

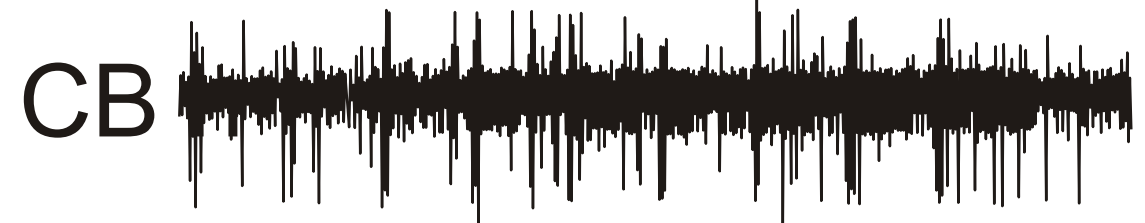


A

Dep MN

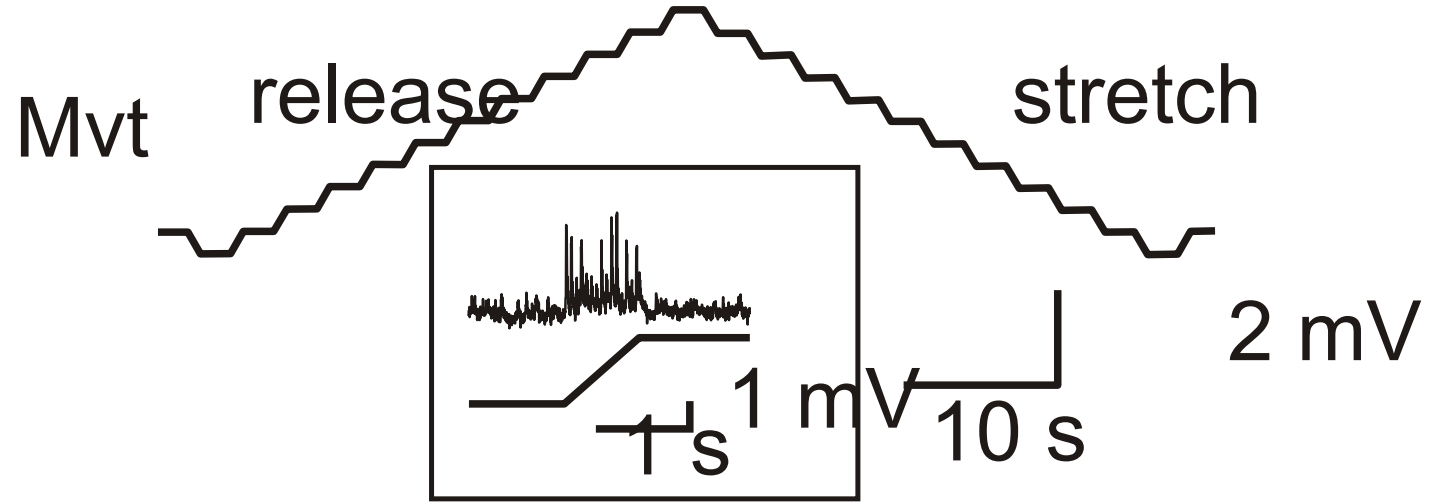

B

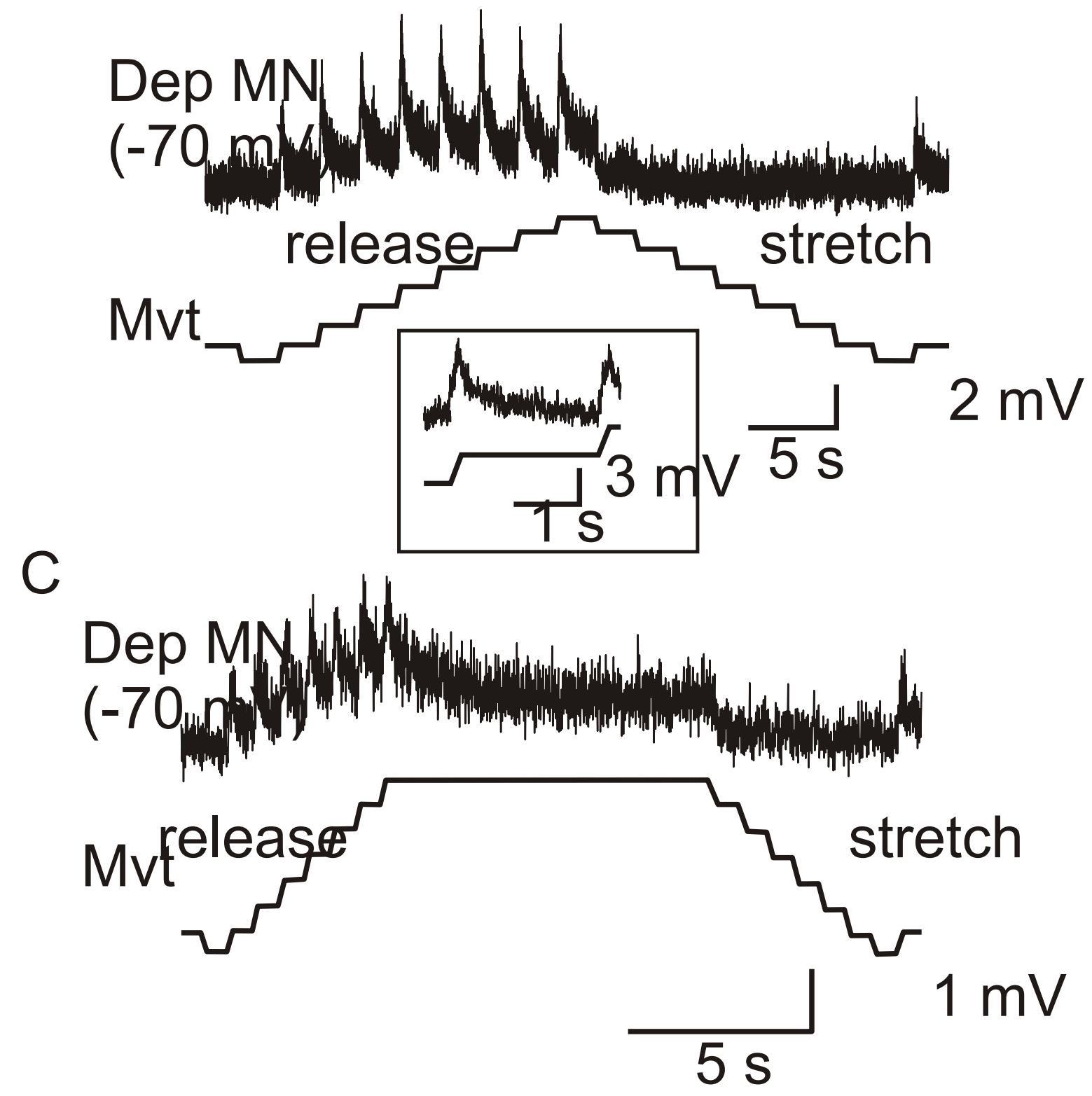


A

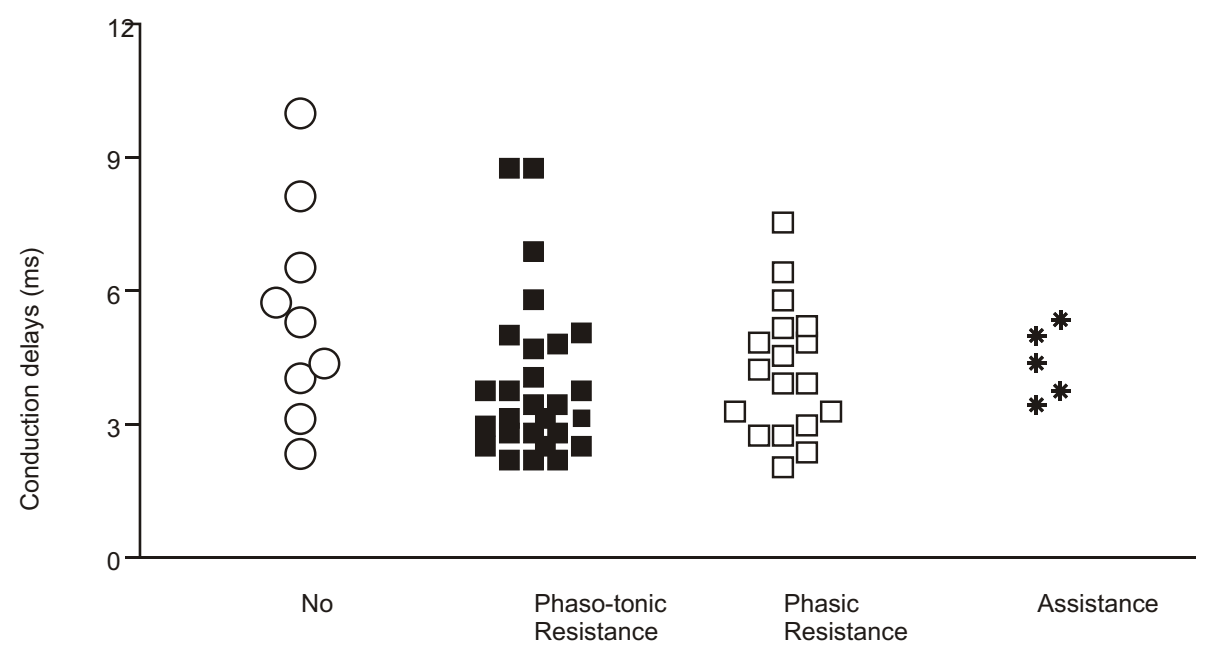

B

Monosynaptic reflex response
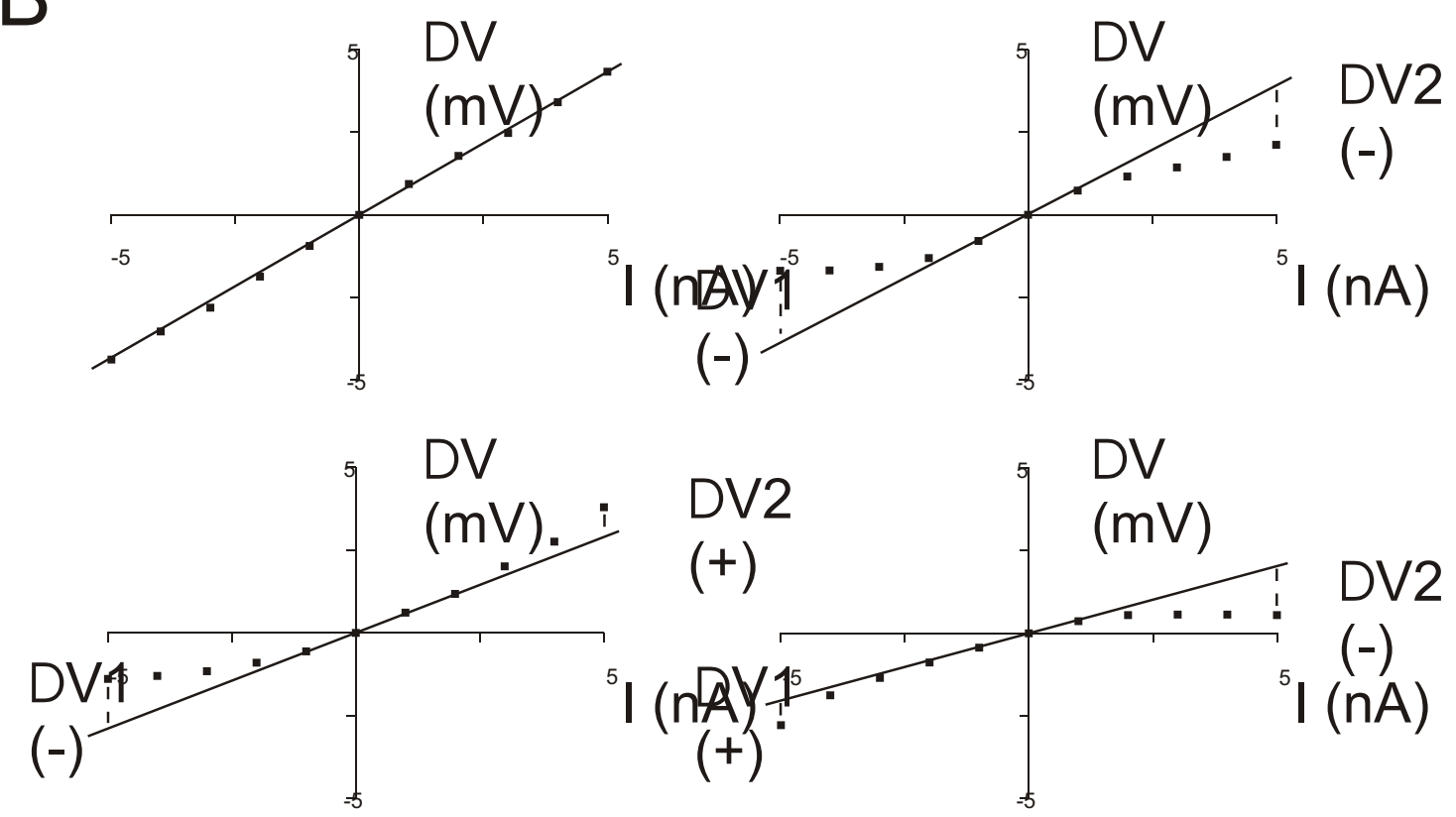

C

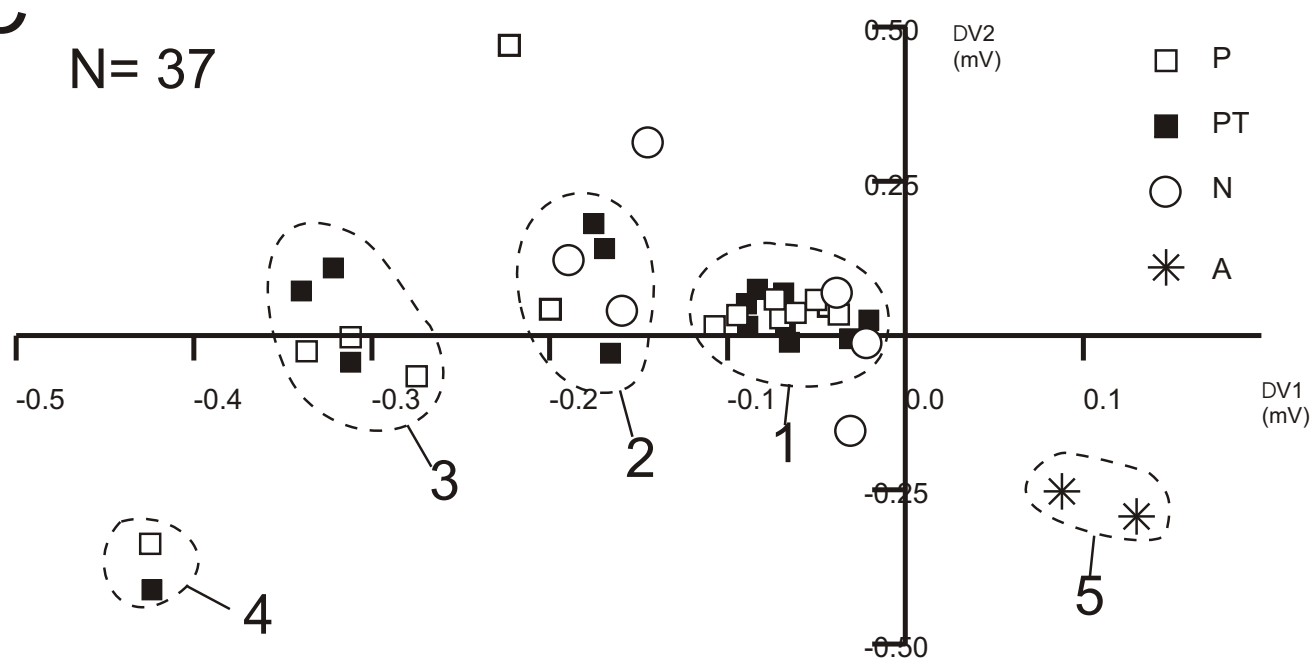

